\title{
Evacuation Response Behaviour of Occupants in a Large Theatre during a Live Performance
}

\author{
Galea, E.R., Deere, S.J, Hopkin, C.G., and Xie, H. \\ Fire Safety Engineering Group, University of Greenwich, UK
}

\begin{abstract}
This paper presents the results of an unannounced theatre evacuation involving 1200 people. The evacuation took place towards the end of a live theatre performance in the Marlowe Theatre in Kent UK. In particular, Response Phase behaviours are discussed and response time data is presented. A significant finding of this work which is different to other reported work is that the occupant response time distribution, while following the typical log-normal distribution is related to the geometrical positioning of the occupants relative to proximity to exit aisles and exits. Response time is found to increase relative to seat distance from the exit aisles and distance of the seat row to an exit. The identified trends in response time distribution will have a profound impact on the analysis of evacuation times and congestion levels determined using agent based evacuation models and so should be represented within these models. Based on these findings, a generalised methodology is proposed to distribute response time within a theatre for use in evacuation simulation applications. Further experimental analysis is required to determine whether these observations can be generalised and applied to other seated venues such as cinemas, music venues and sports arenas.
\end{abstract}

\section{KEYWORDS:}

Evacuation, simulation, response time, human behaviour, theatre, unannounced evacuation.

\section{INTRODUCTION}

The evacuation process is generally considered to comprise two broad phases, here called the Response Phase and Evacuation Movement Phase [1-3] (see Figure 1). During the Response Phase occupants receive a number of early incident cues and/or alerts and after some time they respond to these cues and eventually disengage from their pre-incident activities. However, in most cases, prior to starting decisive evacuation movement they decide to undertake a variety of activities such as; packing belongings, searching for others, investigating the cues, seeking confirmation from others, etc [4-6]. All of this serves to postpone the start of decisive evacuation movement. The duration of the Response Phase is here called the response time, sometimes also confusingly referred to as pre-evacuation time or pre-movement time. Both alternative terms inaccurately describe the nature of the duration of the Response Phase, as the Response Phase is part of the evacuation process (hence not pre-evacuation) and during the Response Phase people can be physically moving but not decisively moving towards an exit or place of safety (hence not pre-movement) and so these terms are not used by the authors.

While several frameworks have been developed to describe Response Phase behaviour [6, 7] here we adopt a framework that not only provides a consistent method for describing Response Phase behaviour, but also provides a useful framework for classifying and quantifying the Response Phase. 
The framework categorises occupant responses into three stages: Notification, Cognition and Activity; where the Cognition and Activity Stages run in parallel [1-3] (see figure 1). This framework is useful as it allows the different types of behaviours exhibited during the Response Phase to be identified so that their relative contribution to the overall response time can be assessed and quantified. This framework differs from previous frameworks in that it represents behaviour during the Response Phase as a three stage process rather than a two stage process (as in [6]) and differs from the conventional three stage concept by not assuming that each stage occurs sequentially (as in [7]). Furthermore, the framework characterises behaviours in the Response Phase as being specifically either action or information related activities. The framework has previously been applied to the analysis of response behaviours for the WTC evacuation [1], university libraries [1-3], evacuation in retail premises [1] and passenger ship evacuation [8]. The three key stages of the Response Phase within the proposed framework consist of:

\section{Notification Stage:}

The first stage of the Response Phase is the Notification stage (see figure 1). In the Notification stage, notification cues, such as an alarm, conveys to the occupants that an unusual and potentially hazardous event has occurred, requiring the occupants to evacuate. The notification cues may be a traditional alarm such as an alarm bell, a voice alarm, intervention by staff or environment cues such as the smell of smoke etc. The start of the Notification stage is marked by the occupants being exposed to the first cues. During the Notification stage the occupant may (knowingly or unknowingly) ignore the cues and continue with their normal activities as they have not accepted or recognised that the cues are relevant to their situation. For each exposed occupant, the end of the Notification stage is marked by the occupants responding to the notification cues by mentally and/or physical disengaging from the tasks they were previously involved in and the recognition that the cue(s) they have been subjected to indicate that something unusual may be occurring in their environment. At the end of the Notification stage, while the occupants are alerted that something unusual is occurring, they have not started to physically react to the situation. The end of the Notification stage marks the beginning of the Cognition stage.

\section{Cognition Stage:}

During the Cognition stage the alerted occupants interpret the information provided by the initial notification cues, and potentially other sources of information (e.g. further incident related cues, staff intervention, etc), and decide how they should respond (see figure 1). There are essentially three broad types of response the occupant may decide to undertake:

- In the first type of response, the initial notification cues have been insufficient to convey to the occupant the immediate need for evacuation and so the occupant reengages in their previous activity until further cues or information is received. In this case, the Cognition stage continues until one of the other two possible responses occur.

- In the second type of response, the occupant has recognised the initial notification cues and as a result, immediately commences evacuation movement without undertaking any other activity. Alternatively, the occupant may have ignored the initial notification cues and re-engaged in their pre-notification activity but then acknowledges additional cues and as a result immediately commences evacuation movement without undertaking any other activity. In these cases the end of the Cognition stage also marks the end of the Response Phase and the beginning of the Evacuation Movement Phase. 
- In the third type of response, the occupant acknowledges that the notification cues indicate that something potentially hazardous is occurring in their environment and as a result undertakes a series of Action and/or Information tasks, marking the start of the Activity stage. In this case, cognitions may be occurring at the same time as activities, activities could be sparking new cognitions and cognitions could initiate one or more new activities. As a result, the Activity stage can run in parallel to the Cognition stage. However, the physical duration of the Cognition stage is less well defined as it may have several possible end points and so is taken to run to the end of the Activity stage.

\section{Activity Stage:}

At the start of the Activity stage the occupant performs a series of Information and/or Action tasks which were conceived during the Cognition stage (see figure 1). These are defined as follows:

- Action task: This involves the occupant physically undertaking an activity such as: shutting down a work station; packing work items; packing/collecting personal belongings in the immediate vicinity; physically moving to another location to perform an action (e.g. fight fire, collect an item).

- Information task: This involves the occupant seeking, providing or exchanging information concerning the incident or required course of action and may include; calling someone on the phone to seek / provide information; seeking / providing information in person; engaging with electronic media (e.g. television, radio, text services, etc); investigating the incident. Thus Information tasks may involve social interaction with others and the physical movement of the occupant. What distinguishes an Information task from an Action task is the end purpose of the movement i.e. to obtain information rather than to undertake a physical task.

It is suggested that the Cognition stage runs in parallel to the Activity stage, and so the occupant may return to the Cognition stage to interpret new information gained, assess their current situation and contemplate their next course of action, which may in turn require further Action/Information tasks to be executed. Thus, during the Activity stage, there may be brief periods where the occupant appears to be undertaking no specific task. The start of the Activity stage is marked by the commencement of the planned tasks while the end of the Activity stage is marked by the completion of all tasks conceived during the Cognition stage. The end of the Activity stage usually denotes the end of the Response Phase and the beginning of the Evacuation Movement Phase. It is only at the start of the Evacuation Movement Phase that the occupant begins their purposeful movement to an exit or stair or place of safety.

The response time is thus seen to be dependent on a number of separate but distinct behaviours, the time required to disengage from the pre-alarm activities (notification time) and the time required to contemplate (cognition time) and complete all of the action and information tasks (activity time) required prior to starting decisive movement to the exit or place of safety. The activity time is dependent on the number of action and information tasks undertaken and the average duration of these tasks. In this paper a modified form of the framework is developed for the analysis of a theatre evacuation. 


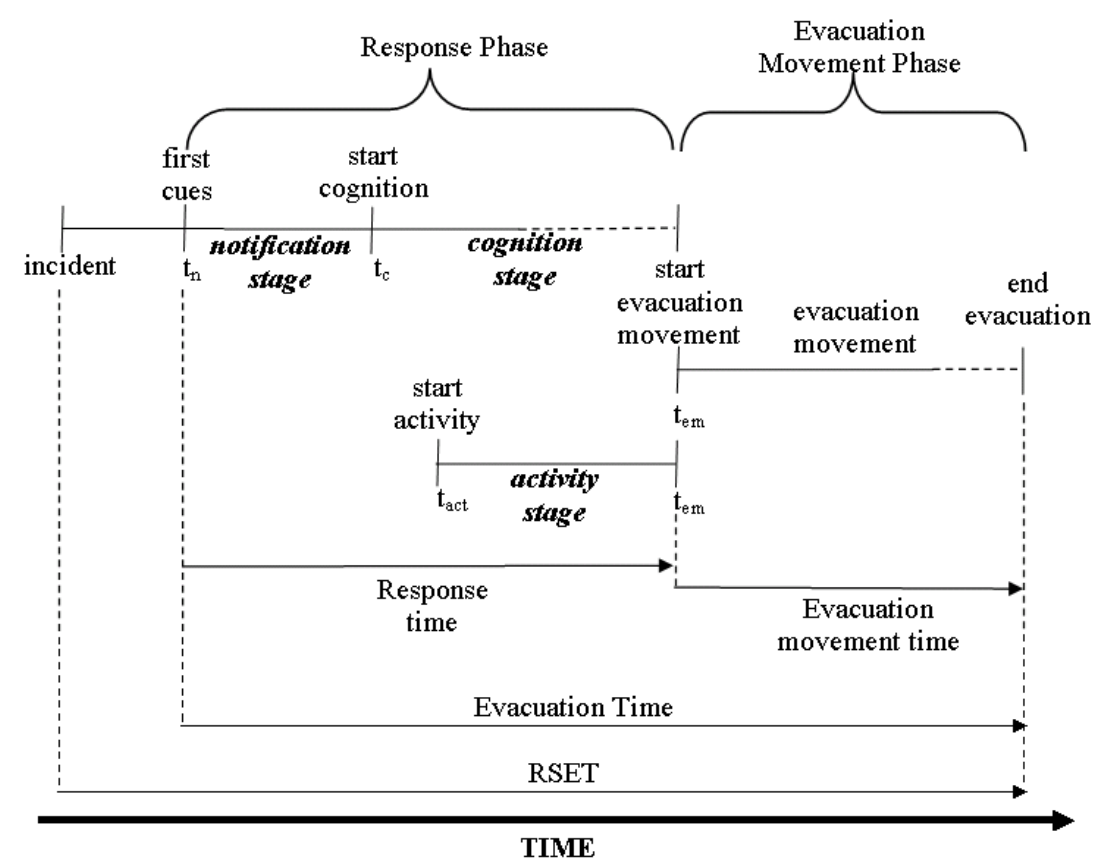

Figure 1. Framework for describing evacuation behaviour.

The way a population reacts to an evacuation alarm is dependent on a number of factors such as population size and distribution, population demographics, interpersonal relationships, prior evacuation experience, training, building familiarity, alarm type, nature of cues received, nature of pre-alarm activities, etc [1,2]. These will in turn impact the notification time and/or the number and type of action and information tasks undertaken and hence the overall activity time. The nature of the building will influence many of these factors, so that a given population exposed to a particular type of alarm may display different Response Phase behaviours (influencing notification time and the number and type of Action and Information tasks undertaken and hence the activity time) if they are in, for example, an office building, rail station, or shopping mall $[1,2]$. This in turn will influence the response time distribution exhibited by the population.

Knowledge of the correct response time distribution to use in evacuation analysis for building design and certification is essential, especially when using multi-agent based evacuation simulation models. If an inappropriate response time distribution is used, not only will the predicted overall evacuation times be inaccurate, severe congestion may be predicted where none exists in reality and congestion regions which may occur in reality may be overlooked.

While some effort has been expended in developing theoretical [9] and empirical models [2, 3] models to predict response times, the engineering community is still reliant on data measured in real world incidents or experiments. While much work has been reported in the literature concerning response times in office buildings, school buildings, libraries, rails stations, department stores and even bars [2, 3, 10-14], seated spaces such as theatres, cinemas and stadia have attracted far less attention.

A series of evacuation trials in a small cinema were undertaken in Sweden $[12,15]$ to determine the impact of the type of alarm system used. A total of 18 evacuation trials were conducted involving some 1872 participants in a 135 seat cinema in Malmo. The alarm was sounded once the initial advertisements had ended and just prior to the main attraction commencing. Therefore the alarm was sounded when nothing was displayed on the screen. 
It is reported that the vast majority of the participants had a relatively short response time, responding in less than 40 seconds. The Response Phase framework introduced above may provide a means for explaining the short response time observed in this experiment. As the participants were gazing at a blank screen at the time of the alarm, they were not yet fully engaged in their intended activity i.e. watching the feature attraction. Thus it is likely that they rapidly disengaged from their pre-alarm activity producing a relatively short notification time which contributed to the short response times observed. Furthermore, given the nature of the environment i.e. a relatively small cinema, it is unlikely that the occupants needed to perform many Action or Information tasks prior to evacuating which would have contributed to a relatively short Activity Stage.

A subset of data from these trials was later analysed to explore the impact of social influence of close neighbours on response time [16]. The analysis involved the data from two types of trials using two types of alarm, a traditional bell alarm and a voice alarm. In this analysis the cinema population varied in size from 88 (65\% occupancy) to 135 (100\% occupancy) with the two trials associated with the bell alarm involving 88 and 100 occupants, while the three trials involving the voice alarm involving 113, 135 and 135. The results suggest that when using a voice alarm, over $90 \%$ of the population have a response time of between $20 \mathrm{~s}$ and 40 $\mathrm{s}$ and a recognition time of between $12 \mathrm{~s}$ and $30 \mathrm{~s}$. In the paper the term recognition time is used to represent the time interval between the sounding of the alarm and performance of action tasks. Thus the recognition time includes the notification time plus the time to complete information tasks such as look around to gather information. Hence the notification time is expected to be less than the reported recognition time - which is quite short supporting at least part of the earlier conjecture.

The results from this analysis did not show a relationship between response time and relative location within the cinema. However, the authors did report that response time for an individual was related to that of a neighbour, so that participants acted more like their neighbours than to others. Thus if a person reacted quickly it was likely that their neighbour reacted quickly. This is not surprising as it is likely, as reported in the paper, that at least one of a participants neighbours was in a social relationship with the participant (e.g. friend, partner, etc). Furthermore, it is noted that the observed trend in response time does not preclude the possibility that response time may also be related to position.

The explanation provided in [16] for the observed trends in response time was the impact of social influence. They equated social influence with the number of people who turned around to look at others. Turning around was defined as a turn of the head of at least 90 degrees prior to the commencement of any Action Tasks. However, from simply analysing video footage it is not possible to determine if people were turning to look for environmental information such as the presence of smoke or flames or even to reassure themselves that the main cinema exit (the way they entered the cinema), which is located in the rear of the cinema, was still available and viable. Thus the observed turn of the head may have nothing to do with social influence, being primarily to collect environmental information. Furthermore, the degree of head turning, at least in the trials involving the voice alarm was very low, with approximately $11 \%$ of the population displaying this type of action. It is also noted that the nature of the experiment i.e. sounding the alarm prior to the start of the main attraction and hence prior to the commitment of the participants to their intended activity may have not only influenced the magnitude of the response times but also the nature of its distribution. Finally, the cinema in the study was very small, consisting of only 135 seats and involving only nine seat rows each with 15 seats. If response time is related to seating 
location it may only become apparent in a larger seating environment. Thus while social influence may be a factor influencing response time, it is not possible to determine from this study how important it may be in determining response time in this specific setting or seated venues in general.

This paper reports on a full-scale unannounced evacuation of the 1200 seat Marlowe Theatre in Canterbury Kent [17] on the $6^{\text {th }}$ April 2013 during a full-house live evening performance. In particular the Response Phase Behaviours and the nature of the response time distribution are described. While the derived response time distribution displays the typical log-normal shape found in most evacuations, unlike the findings of the earlier cinema evacuation data [16], the distribution of response times was found to be highly structured and strongly related to relative location which has significant implications for evacuation modelling applications.

\section{MARLOWE THEATRE AND THE EVACUATION PROCEDURES}

The Marlowe Theatre is a 1200-seat theatre located in Canterbury, England. It consists of two main areas: The Main Auditorium and the Marlowe Studio. The venue is frequently used for shows including plays, musicals, ballet, contemporary dance, opera, as well as other forms of entertainment. The Main Auditorium seating is comprised of three main levels (see Figure 2a), the upper circle (highest level), circle, and stall levels (lowest level). Four exits on the lower tier were used during the evacuation, two located on the left and two on the right adjacent to seat rows $\mathrm{A}$ and $\mathrm{M}$ (see Figure $2 \mathrm{~b}$ ). The theatre had two seat widths depending upon seat location: wider seats were 0.525 metres wide, with the smaller seats possessing a width of 0.505 metres. The distance between rows varied between 0.9 metres to 1.0 metres depending upon row location. Video analysis was performed on occupants of the 12 stall level rows A to M (Figure 2b) of the Main Auditorium, a total of 347 seats - note there is no row i. The general Response Phase analysis was undertaken on occupants throughout this region. At the time of the alarm, this involved 338 individuals for which response times could be determined, 336 seated people consisting of 114 males, 206 females and 16 people of undetermined gender. In addition there were two people of undetermined gender seated in wheel chairs in the aisle between the last two rows, L and M. The lower stalls, consisted of a contiguous block of 320 seats in 11 rows labelled A to L, these were used for the response time analysis concerning relative position. This involved 311 people seated in 11 rows, three of these rows had 32 seats, three rows had 31 seats and the remaining rows had 30, 29, 28, 25 and 18 seats each.

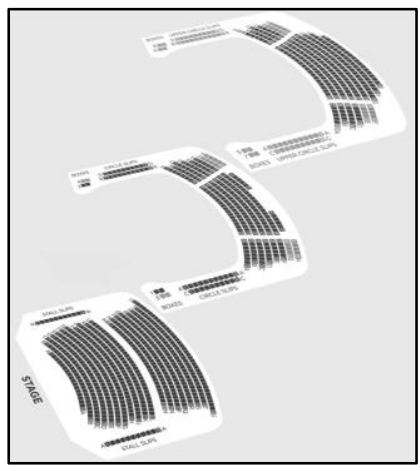

(a)

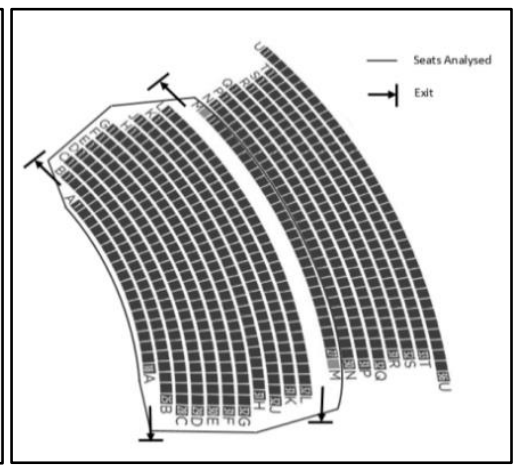

(b)

Figure 2. Seating arrangement in the Marlowe Theatre depicting (a) the general seating arrangement (b) highlighting the study area [18] 
A total of 30 Sony Handycam camcorders were positioned throughout the auditorium, but video analysis was specifically performed on two cameras positioned in the circle slips at circle level, above the auditorium, to show people entering and evacuating at stall level (Figure 3).

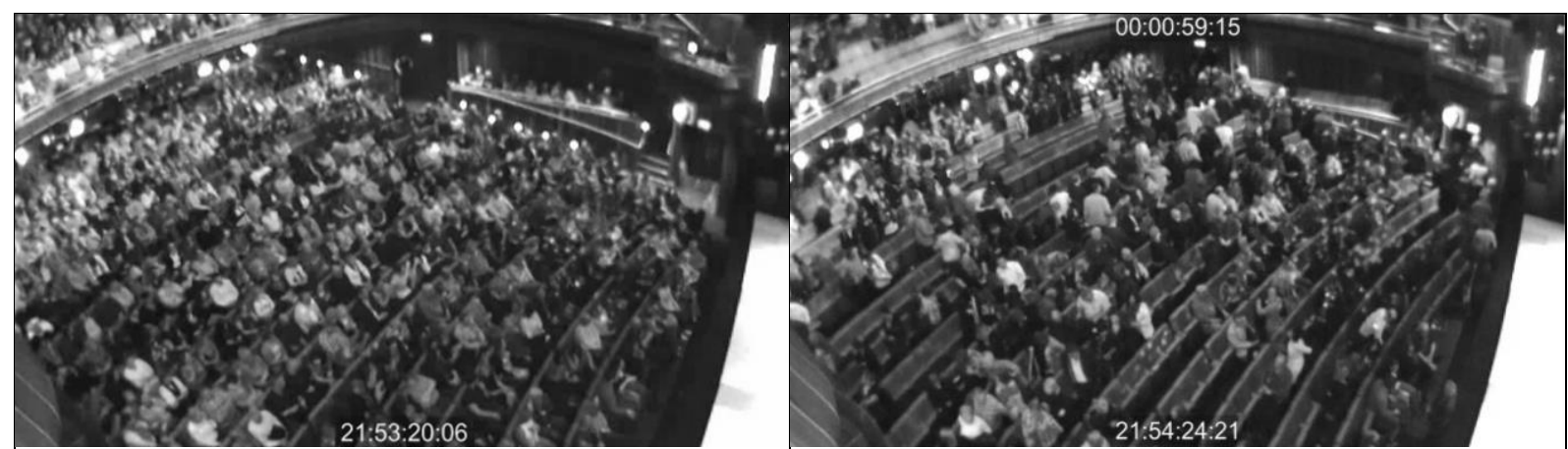

(a) Camera 1 showing a view of the left side of(b) Camera 1 showing a view of the left side of the auditorium prior to evacuation the auditorium almost 1 minute after the start of the evacuation

Figure 3. View of the Marlowe Theatre Auditorium Prior-to and During Evacuation

The main entrances to the theatre complex are located on the right side (when facing the stage) of the auditorium (see Figure 4). Thus all the patrons would have entered the theatre complex from the right side and so would be aware that this was the main exit point. Furthermore, from the video analysis of the population entering the auditorium, it was noted that more than $84 \%$ of the population located in the stalls region (study area) entered from the right side exits. Thus the majority of the study area population would be familiar with the right side exits from the auditorium and all of the population would be familiar with the right side exit from the theatre complex.

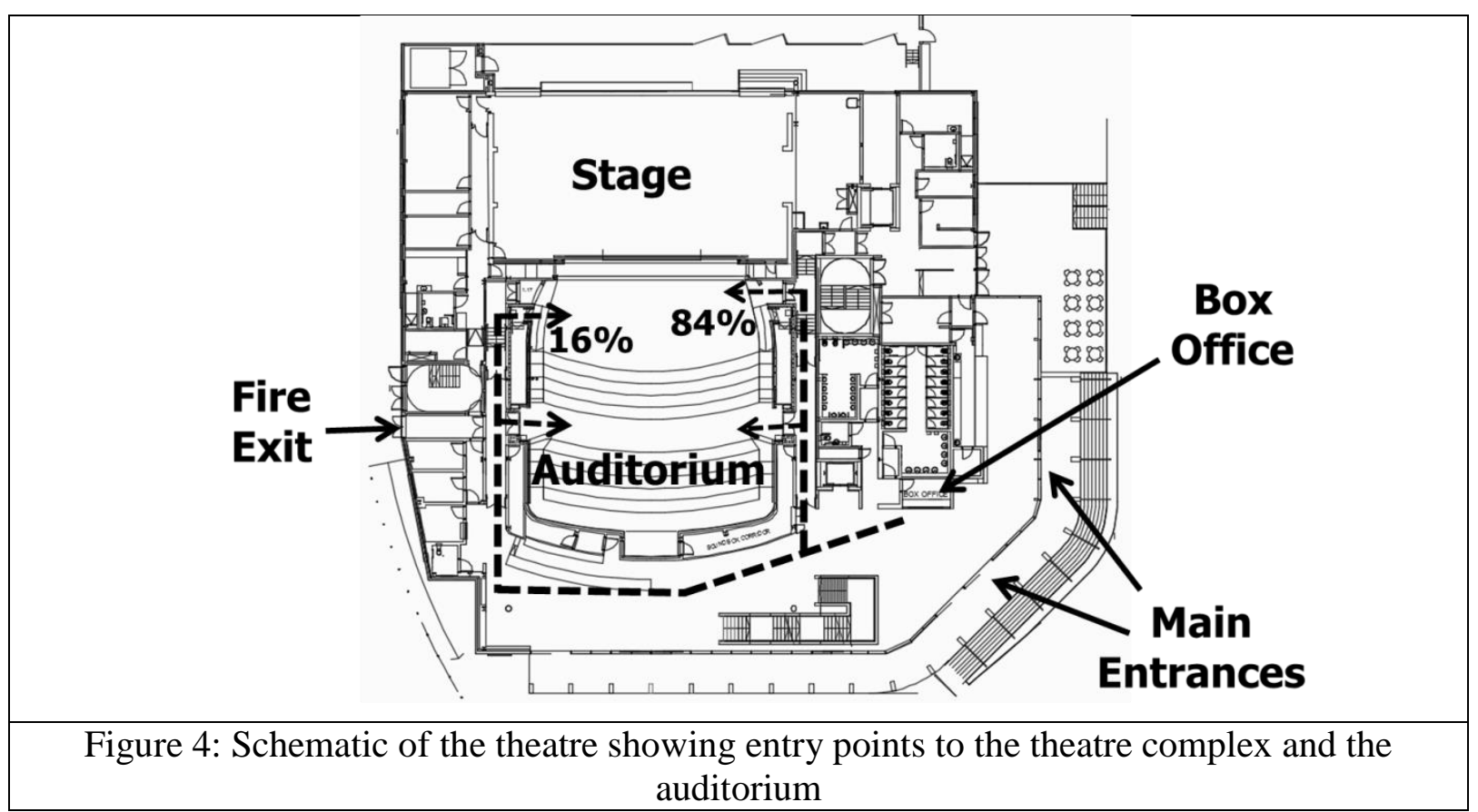


The evacuation trial took place near the end of an evening performance of the musical theatre production of 'Dirty Dancing' on Saturday $6^{\text {th }}$ of April 2013. The alarm first sounded within the auditorium at 21:53:23, with the voice message starting at 21:53:25. The evacuation alarm had two phases. In the first phase, fire doors were shut and buzzers, which could not be heard by the audience, were sounded outside the auditorium. In the second phase, all lights went to maximum brightness within the auditorium and, following a period of a few seconds, a manually activated pre-recorded message was broadcast in the auditorium. The prerecorded message consisted of a male spoken voice which repeated the following statement: "In the interest of your safety we must stop this performance and must evacuate the building immediately. Please leave the building using only the exits indicated by our staff." The message, including pause at the end takes $15 \mathrm{~s}$ before it is repeated. A steel safety curtain, which is part of the stage, also descended during the voice alarm. In addition, a number of fire appliances from Kent Fire and Rescue Service arrived on the scene with sirens active adding to the authenticity of the incident.

\section{TERMINOLOGY AND METHODOLOGY}

Based on video footage alone it is not possible to determine Cognition times and so here it is assumed that the Cognition and Activity stages occur in parallel and start and end at the same time. Furthermore, given the size of the theatre and the number of video cameras available it was necessary to zoom out so that as much of the theatre could be viewed using as few cameras as possible. Thus it was not possible to easily determine the nature of all the activities individuals were engaged in during the Activity Stage, particularly the Information Tasks. It was not possible to determine for example if a person was speaking to their neighbour or what a person was looking at when turning their head to gaze in a particular direction or if a person was gazing in a particular direction while talking to their neighbour, thus engaged in potentially several Information Tasks at once. However, it was considerably easier to determine the nature of Action Tasks, such as picking up belongings.

Thus in this paper the categorisation of the Response Phase behaviour is adapted to accommodate the deficiencies of the data collection process and the special nature of the behaviour exhibited evacuation scenarios involving seated venues.

The term Recognition Time is introduced to define the time period from the start of the alarm to the start of the Activity Stage. It includes the Notification Time from the standard framework plus the time period where participants are performing initial Information Tasks prior to the start of Action Tasks within the Activity Stage. From the analysis of the video footage it is clear that a considerable number of people were engaged in Information Tasks shortly after the alarm was sounded and the lights were turned on due to the high level of noise generated from conversations and from various body movements displayed by the audience while still seated. However, as already explained it was not possible to identify the type or number of Information Tasks being performed and so these specific Information Tasks are not measured.

During the Recognition Time, participants are disengaging from their pre-alarm activity (Notification Stage) and assessing the physical environment and the behaviour of others (performing Information Tasks). The end of the Recognition Time marks the start of the Activity Time and is identified when participants are seen to begin Action Tasks while still seated or have motioned to stand up. 
During the Activity Stage only the Action Tasks performed by the participants are measured. While Information Tasks may also be occurring during the Activity Stage, their number and type are not recorded. Thus a person can appear to undertake no Action Tasks but still have a non-zero Activity Time as they are engaged in some kind of Information Task e.g. talking to others or observing others or the environment prior to starting decisive movement towards an exit. The Activity Start time was identified as the time when a person showed signs of beginning physical Action Tasks while seated, i.e. they had fully acknowledged the alarm and began physically preparing for evacuation or the time at which they have stood up at their seat location, whichever is the smallest. The Activity End time was identified when a person was standing, appeared to have completed all Action Tasks, turned their body to face the direction of travel and appeared to be in a position where they were ready to start decisive movement towards an exit. It is acknowledged that during the Activity Stage, participants may still be performing Information Tasks, so while the number and type of these tasks was not measured, the Activity Stage could extend beyond the completion of Action Tasks.

The end of the Activity Stage usually marks the end of the Response Phase and the start of the Evacuation Movement Phase. However, within the seating rows of the theatre, Movement Delays may occur between the completion of the Activity Stage (end of the Response Phase) and the start of the Evacuation Movement Phase. This is usually the result of factors such as delays caused by seating row neighbours having not yet completed their Response Phase, congestion within the seat row or due to congestion in the aisles at the end of the seat rows preventing evacuation movement. Thus while the participant has completed their Response Phase, they may be unable to begin movement from their initial seating location towards the exit. While not reported here, in this work the Time to Start Evacuation Movement is defined as the sum of the Response Time and the Movement Delay and provides an indication of the total time that a person remains at their seat location following the sounding of the alarm. The modified and new terms are presented in Figure 5.

As part of this analysis the following data was collected from the video footage: gender, row number, seat number, the Activity Start Time, Standing Time (the time at which the person stood up), Activity End Time (the time at which the person appeared to be in a situation where they could begin movement), Movement Time (the time at which the person began moving and End Row Time (he time at which the person reached the end of their seating row). Also recorded were observations on a person's chosen direction of exit (left or right), the number and type of Action Tasks performed as part of the Activity Stage, and any noticeable reasons for differences in a person's Activity End time and Movement Time.

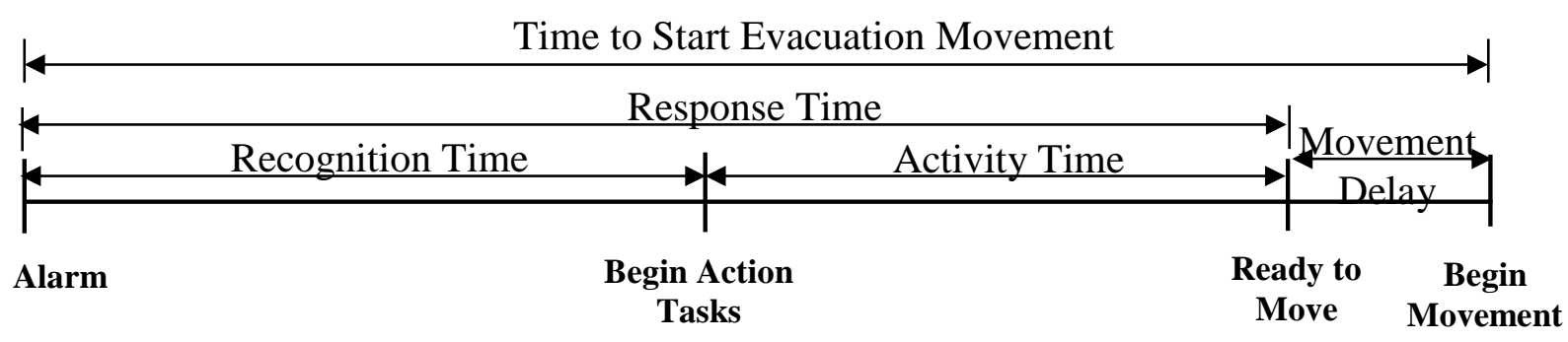

Figure 5. Response Phase for Theatre Population

The five key times in this analysis can be summarised as follows:

- Recognition Time: The time from the start of the alarm to the time that a person begins performing an Action Task or stands up, whichever is smaller. The end of the 
Recognition Time begins when a person is seen to perform a physical action, such as gathering or packing items while seated. If a person does not perform any Action Tasks while seated, the end of the Recognition Time occurs when the person stands.

- Activity Time: The time required by a person to perform all of their preparation activities and be considered ready to make decisive movement towards an exit. It is the difference between the time when a person is seen to begin an Action Task or stand up (Activity Start Time) and the time when a person is considered to be ready to decisively move towards an exit (Activity End Time). The Activity Time can be measured for those who begin or undertake an activity while seated or standing. The Activity time cannot be zero as there is always a non-zero time between standing and turning to begin decisive evacuation movement.

- Response Time: This is the time from the start of the alarm to the end of the Activity Stage and hence is a measure of the time required to be able to begin purposeful movement to an exit.

- Movement Delay: This is the difference between the time people begin purposeful movement towards an exit and the end of the Activity Stage where one exists or the end of the Recognition Stage where there is none i.e. the end of the Response Phase.

- Time to Start Evacuation Movement: This is the time from the start of the alarm to the time where a person begins purposeful movement towards the exit.

\section{OBSERVATIONS AND DISCUSSION}

In total there were 338 people in the stalls, 114 males, 206 females and 18 people of unknown gender two of which were disabled. Due to the nature of the performance, the majority of the audience were female adults and this is reflected in our sample. Also, due to the time of day and time of year (middle of a Northern Hemisphere Spring), many people had coats. In addition, three members of the audience (sitting together in row 6 seats 1, 2 and 3) commenced their Response Phase prior to the sounding of the alarm and so their behaviour is not considered in this analysis. The behaviour of the population during the Response Phase will be examined by systematically exploring the response of the population during each of the identified Response Phase Stages.

\section{Recognition Stage}

The start of the alarm sequence (the tone component) is heard in the auditorium at 21:53:23, with the voice message starting at 21:53:25. A few people are seen to almost immediately begin performing Action Tasks (very short Recognition time) from the start of the alarm sequence. The auditorium erupts into laughter $13 \mathrm{~s}$ after the start of the alarm tone and during the first voice loop of the alarm, suggesting that some in the population consider that the alarm may be a practical joke. Considerable talking is then heard as the population perform Information Tasks, discussing and visually assessing the situation. The majority (64\%) of the population have completed their Recognition Stage $20 \mathrm{~s}$ to $40 \mathrm{~s}$ after the start of the alarm sequence.

Recognition data could be determined for a total of 299 people, 100 males, 190 females and 9 people of unknown gender. The recognition times varied between $1.1 \mathrm{~s}$ and $89.9 \mathrm{~s}$ with a mean of $31.2 \mathrm{~s}$ (see Figure 6). The mean recognition time for the male population (33.9 s) was $14.5 \%$ longer than that for the female population $(29.6 \mathrm{~s})$. This difference is statistically significantly different (Mann-Whitney $\mathrm{U}=11454, \mathrm{n} 1=190, \mathrm{n} 2=100, \mathrm{P}<0.01$, two tailed). The Recognition delay for the male population varied from $1.9 \mathrm{~s}$ to $89.9 \mathrm{~s}$ while that for the 
female population varied from $1.1 \mathrm{~s}$ to $86.6 \mathrm{~s}$. Thus on average males took longer to disengage from the pre-alarm activity and start to prepare to physically evacuate than females. It is noted that the recognition time includes the notification time and the time to perform a number of Information Tasks prior to starting the Activity Stage.

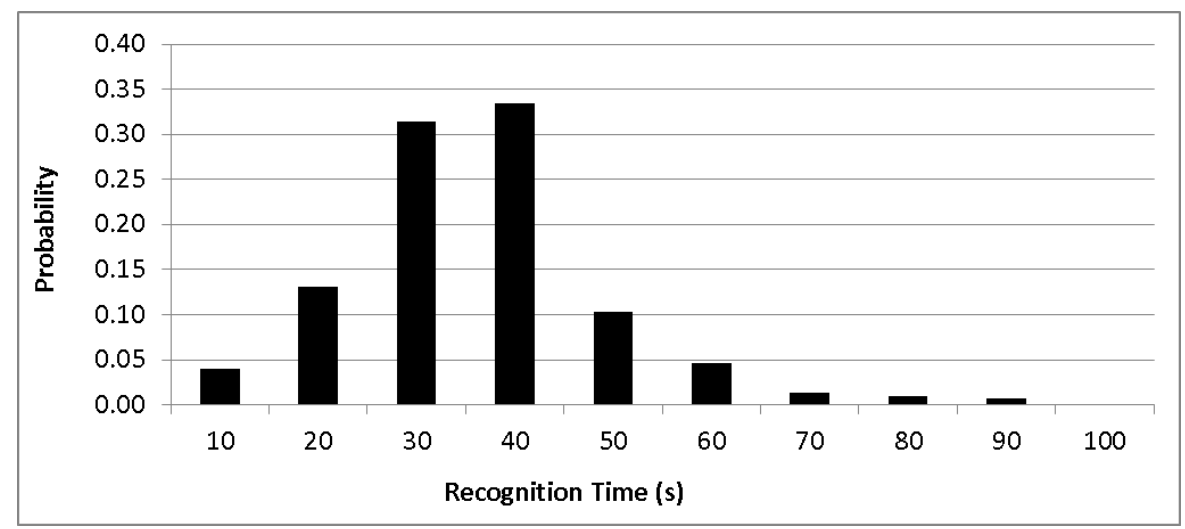

Figure 6: Recognition Time (s) for the theatre population

Given that the Recognition Time includes the Notification Time and the time to perform initial Information Tasks, it is clear that the Notification Time for the theatre audience is quite small. This is to be expected due to the nature of the alarm sequence, involving halting the stage production, raising the theatre lights to full brightness and use of the tone and voice alarm. The audience was left in no doubt that something unusual was occurring resulting in the relatively small Notification Time. The audience then begin to assess the situation undertaking a range of Information Tasks to collect additional information from their environment and from the behaviour of others. While not quantified, it is clear that a number of Information Tasks are being performed by most people once they have disengaged from their pre-alarm activity due to the large amount of noise heard in the theatre (information exchange, questioning, advice seeking) and the amount of physical activity seen as people turn to look around the theatre seeking visual cues to reinforce their response.

\section{Activity Stage}

The Activity Stage was measured for 293 people, 97 males, 187 females and 9 people of unknown gender. Of these, Action Tasks were measured for 145 people, 43 males, 97 females and 5 people of unknown gender. Overall the shortest Activity Time was $0.4 \mathrm{~s}$ with the longest being $80.5 \mathrm{~s}$ with a mean Activity Time of $24.8 \mathrm{~s}$. Almost half the population (44\%) have completed their Activity Stage $20 \mathrm{~s}$ after the start of the Activity Stage (see Figure 7). The average duration of the Recognition Stage (31.2 s) is $26 \%$ longer than the average duration of the Activity Stage $(24.8 \mathrm{~s})$ and this difference is statistically significantly (Mann-Whitney $U=56356, \mathrm{n} 1=299, \mathrm{n} 2=293, \mathrm{P}<0.001$, two tailed). Thus on average people take longer disengaging from their pre-alarm activity and collecting information on the immediate situation than in physically preparing to start to evacuate.

The mean Activity Time for the male population ( $23.3 \mathrm{~s}$ ), while being $7.5 \%$ shorter than that for the female population $(25.2 \mathrm{~s})$ was not found to be statistically significantly different (Mann-Whitney $\mathrm{U}=9616, \mathrm{n} 1=187, \mathrm{n} 2=97, \mathrm{P}=0.405$, two tailed). The Activity Time for the male population varied from $1.1 \mathrm{~s}$ to $60.0 \mathrm{~s}$ while that for the female population varied from $0.4 \mathrm{~s}$ to $80.5 \mathrm{~s}$. Thus on average females take longer to physically prepare to evacuate than males. The gender difference between the Recognition and Activity Times is quite large, with males taking $31 \%$ longer to disengage and collect information than to physically prepare 
to start to evacuate while for the females the difference is only $15 \%$. Thus while both males and females take longer thinking about starting the evacuation process than physically preparing to start to evacuate, males spend proportionally more of the Response Time involved in thinking about the process than females.

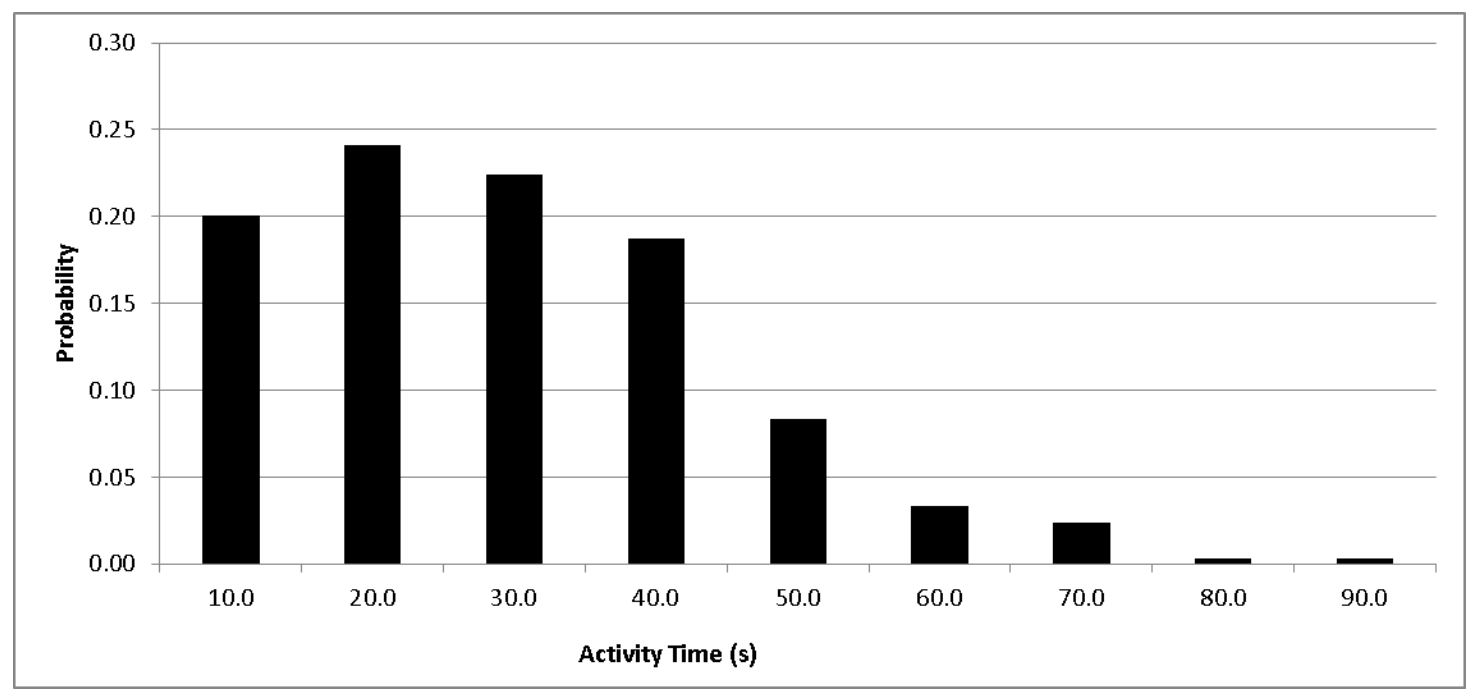

Figure 7: Activity Time (s) for the theatre population

Presented in Figure 8 is a comparison of the male and female Activity Time distributions. While $85 \%$ of the female population and $86 \%$ of the male population have completed the Activity Stage within $40 \mathrm{~s}$, the female population has a greater proportion displaying long Activity Times. Thus a small number of the female population is responsible for incurring the long Activity Times.

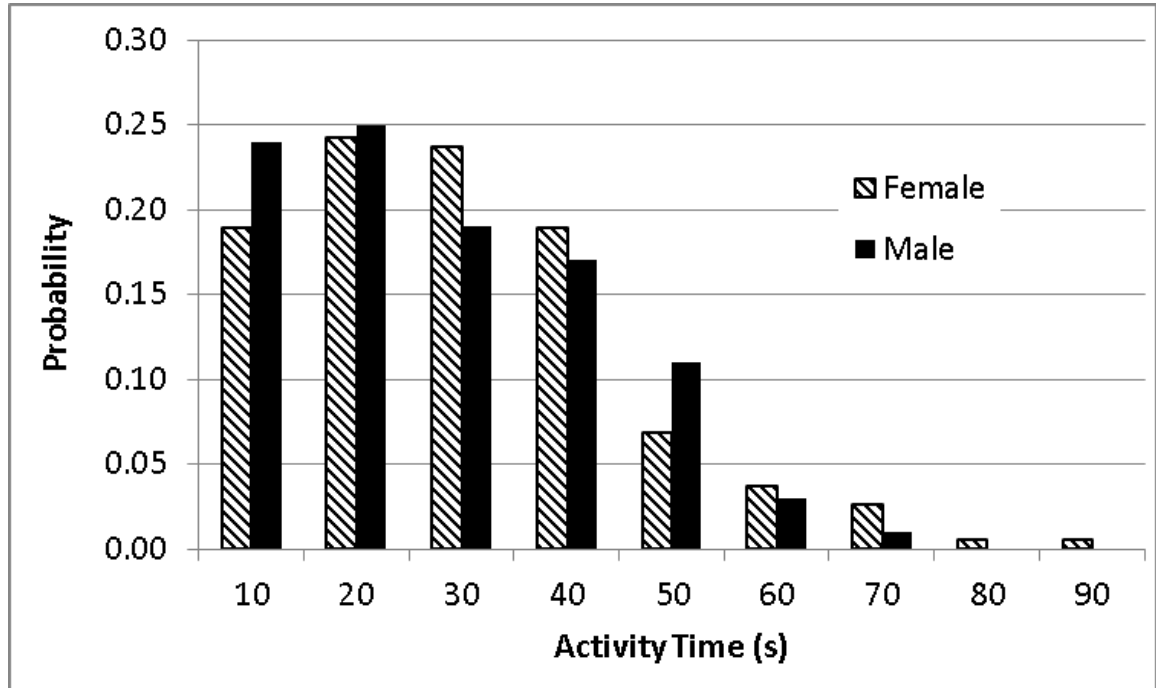

Figure 8: Activity Time (s) for male and female theatre population

Where possible, Action Tasks performed as part of the Activity Stage were identified (see Figure 9). In total 194 Action Tasks were identified with the most frequently observed Action Task being gathering or putting on a coat (64\% of all actions), with 125 people (39\% of the population) recorded as performing this task. It is noted that collecting a coat and putting on a coat was counted as a single task, so people could have collected a coat and not put it on, or collected a coat and put it on, both of which was considered a single task. Given that the evacuation occurred in the Northern Hemisphere Spring during the late evening, the 
high number of action tasks associated with putting on coats is not surprising. The coat task represented $64 \%$ of all the Action Tasks identified. Had the evacuation taken place during the summer or during the day it is possible that fewer people in the audience would have had coats. This in turn would greatly reduce the number of Action Tasks performed, decreasing the duration of the Activity Stage and hence the overall Response Time (RT). Thus the RT for a theatre evacuation may be influenced by the time of day and season of the year in which the evacuation takes place. Clearly the geographical location will therefore also potentially impact the RT distribution as certain regions may be hotter or colder than Kent in the UK requiring more or less warm clothing.

The second most frequently observed task involved picking up a bag or gathering items and placing them in a bag (43 people) which represented $22 \%$ of all the tasks. 18 people were observed to be putting on a scarf and 4 people were observed assisting others, e.g. helping another person put on a coat.

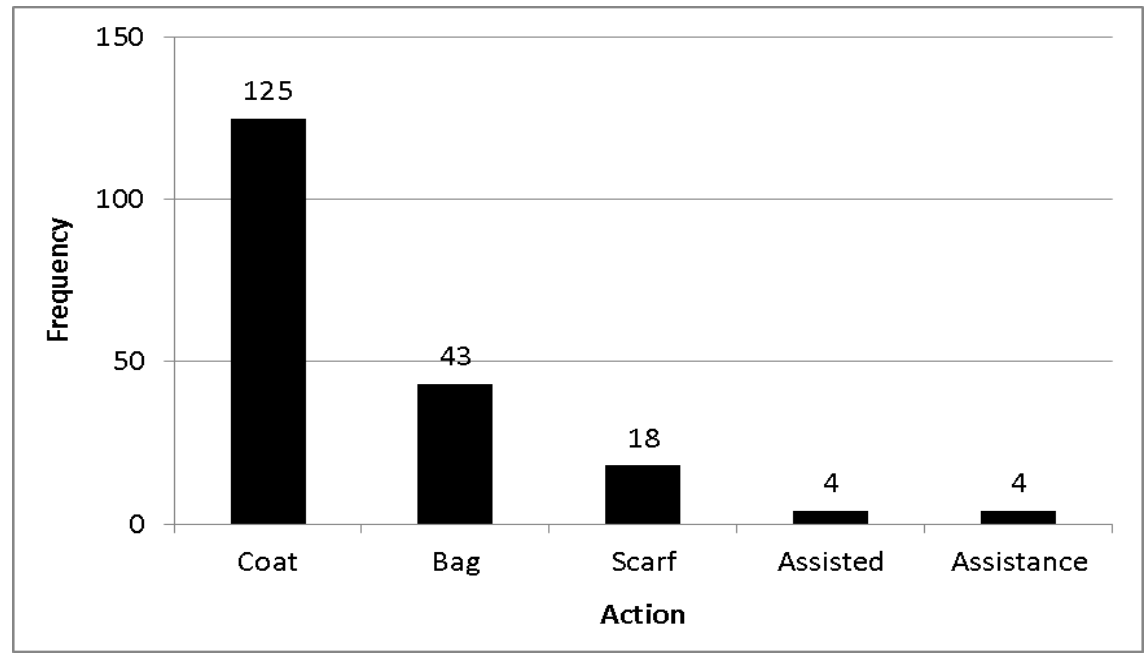

Figure 9. Common activities performed during evacuation

In terms of the number of Action Tasks performed by individuals during the Activity Stage it can be seen that the majority of people (52\%) did not perform a single Action Task during the evacuation, followed by $36 \%$ of people performing a single task, $10 \%$ performing two tasks, and $2 \%$ performing three tasks (see Figure 10).

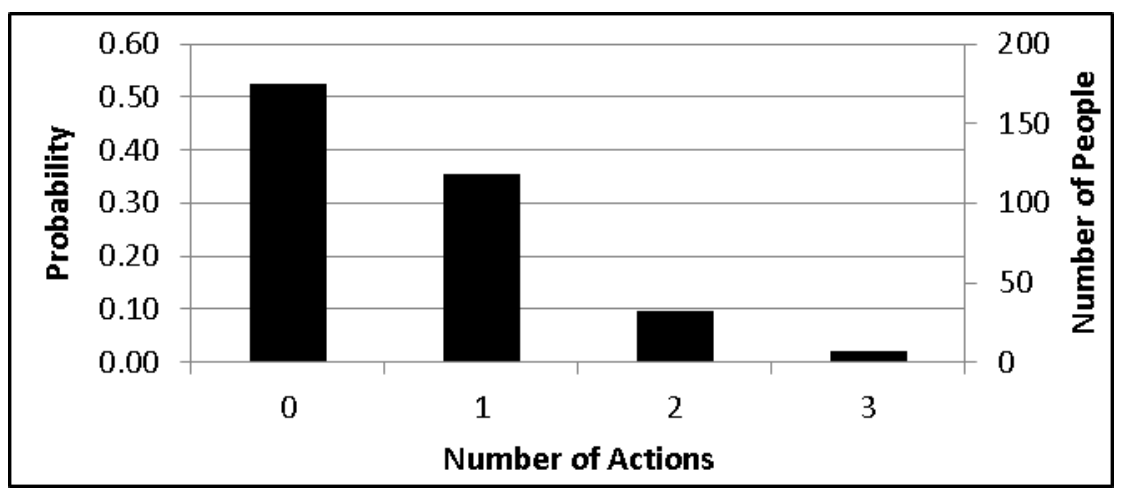

Figure 10. Number of Action Tasks Performed during the Activity Stage

The average number of Action Tasks performed by a person was 0.62 . The number of Action Tasks performed was also analysed by gender to determine if there was a gender bias to the number of Action Tasks undertaken during the Response Phase. For the male population, 
$58 \%$ performed 0 tasks, while approximately $36 \%$ performed 1 task and $6 \%$ performed 2 tasks (see Figure 11). No males performed 3 tasks during the evacuation while the average number of tasks performed by males was 0.47 .

For the female population, $49 \%$ of the population performed 0 Action Tasks while $4 \%$ performed 3 Action Tasks (see Figure 11). On average females perform 0.70 Action Tasks prior to starting to evacuate, $49 \%$ more than the males. The longer time females spend on average in the Activity Stage compared to males is due to females undertaking more physical tasks during the Activity Stage. The approximate time to complete an Action Task can be determined knowing the duration of the Activity Time and the number of Action Tasks performed. However, it is noted that this is only considered an approximate time as during the Activity Stage, the participant may also be performing an unknown number of Information Tasks which contributes to their Activity time.

Presented in Table 1 is the average time participants spent performing a number of Action Tasks. From this data the average time for the population as whole to perform one Action Task can be determined. The population as a whole requires approximately $25 \mathrm{~s}$ to complete a single Action Task, with males requiring $26 \mathrm{~s}$ and females requiring $23 \mathrm{~s}$. However, the difference between average time to complete a task for the male and female population is not statistically significantly different (Mann-Whitney $\mathrm{U}=2298.5, \mathrm{n} 1=96, \mathrm{n} 2=43, \mathrm{P}=0.285$, two tailed). Thus, while males complete the Activity Stage $7.5 \%$ quicker than females, they undertake $49 \%$ fewer tasks on average and take $13 \%$ longer on average to complete each Action Task. However it must be emphasised that these times are considered estimates as it is not clear how many Information Tasks were also undertaken during the Activity Stage.

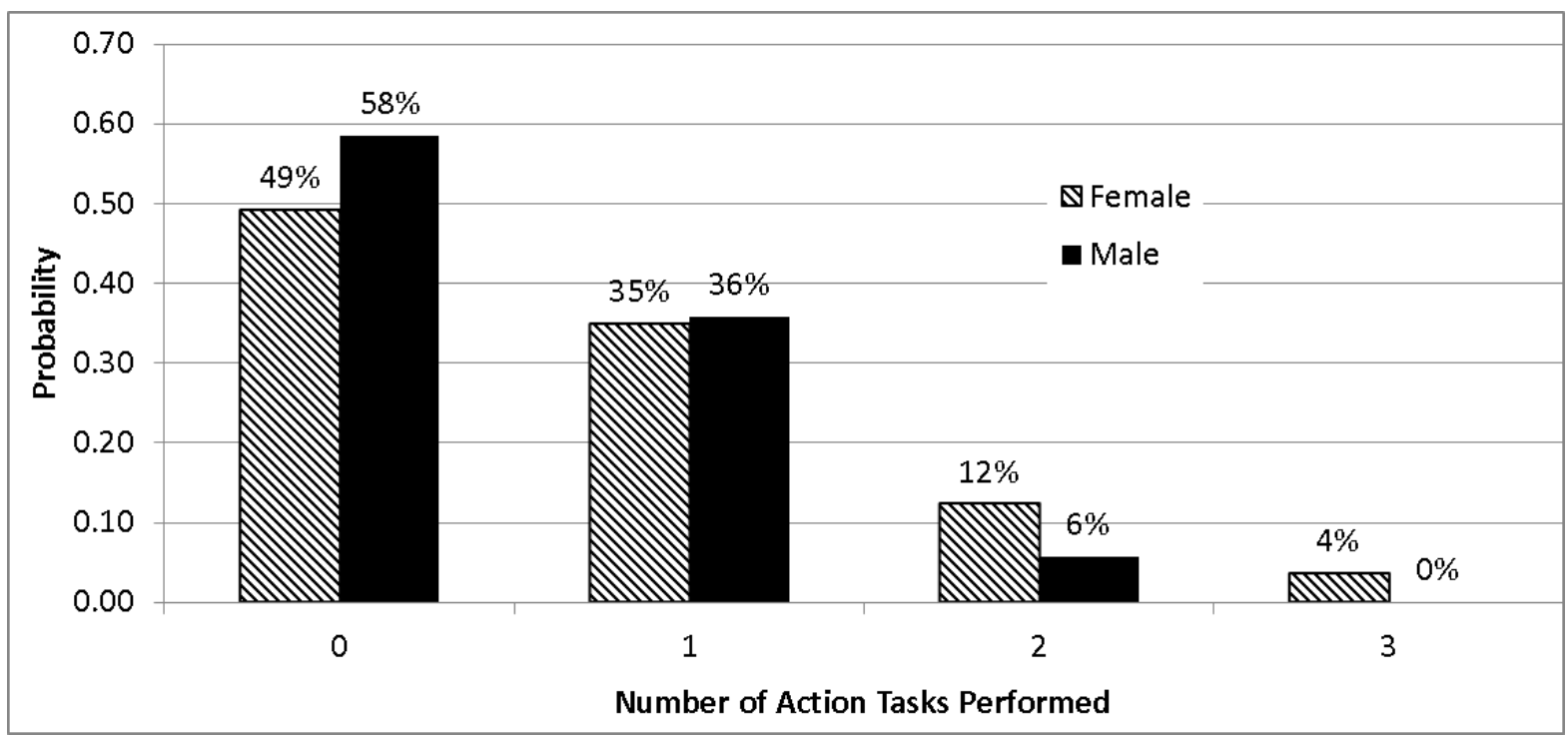

Figure 11. Number of Action Tasks Performed during the Activity Stage by Males and Females

\section{Response Time Frequency Distribution}

Response Time (RT) data was recorded for a total of 335 people, 113 males, 204 females and 18 people of unknown gender. The average RT for the overall population was $62.6 \mathrm{~s}$ which includes the RT for two disabled people (in wheelchairs) and their four helpers $(545.3 \mathrm{~s}$, 
$545.3 \mathrm{~s}, 545.3 \mathrm{~s}, 545.3 \mathrm{~s}, 287.6 \mathrm{~s}$ and $187.6 \mathrm{~s}$ ). Excluding the disabled population and their helpers, the average response time for the population was $55.6 \mathrm{~s}$, thus it took on average about 1 minute for people to respond to the call to evacuate within the theatre.

The RT distribution for the theatre - excluding the disabled occupants and helpers - is depicted in Figure 12 (and equation 1) and follows the typical log-normal distribution with mode between $40 \mathrm{~s}$ and $50 \mathrm{~s}$.

$$
y=\frac{1}{\sqrt{2 \pi}(0.44) x} \exp \left[-\frac{(\ln (x)-3.93)^{2}}{2(0.44)^{2}}\right]
$$

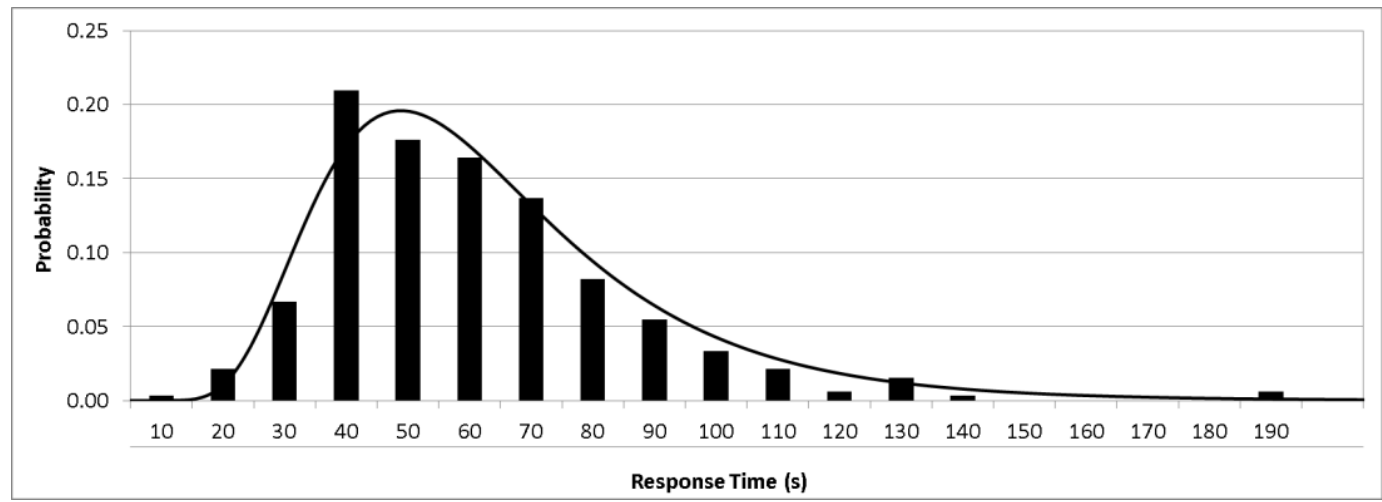

Figure 12. Response time frequency distribution

The response time distributions for the male and female populations were very similar. Excluding the disabled population and their helpers, the minimum male response time was $4.8 \mathrm{~s}$ while the maximum was $183.4 \mathrm{~s}$ with an average of $57.2 \mathrm{~s}$. For the Female population, the minimum response time was $15.0 \mathrm{~s}$ while the maximum was $180.4 \mathrm{~s}$ with an average of $54.9 \mathrm{~s}$. The difference between male and female average RT was not statistically significant (Mann-Whitney $\mathrm{U}=11475, \mathrm{n} 1=204, \mathrm{n} 2=113, \mathrm{P}=0.632$, two tailed).

Presented in Table 2 is a summary of the parameters defining the Response Phase performance of the population. The RT for the population is distributed according to a lognormal distribution with an overall mean RT of $55.6 \mathrm{~s}$. During the Response Phase, the population takes $26 \%$ longer to disengage and assess the situation (Recognition Stage) prior to evacuating than preparing to evacuate (Activity Stage). While the general trends in the male and female populations follow those of the population as a whole, there are some interesting differences.

The male and female populations have very similar overall RT distributions, with the average male RT being some $4 \%$ longer than the average female response time. However, males take 13\% longer than the females to disengage and assess the situation (Recognition Time) but 8\% shorter to physically prepare to evacuate (Activity Time). Thus the longer time males require to disengage is partially compensated by the shorter time they require to physically prepare to evacuate. The reason that males are quicker to prepare is that they do on average $49 \%$ fewer Action tasks while preparing to evacuate than females. However part of this advantage is lost by requiring approximately $11 \%$ longer to undertake an Action task compared to the female population. 
Improving the overall RT for the theatre would require either reducing the Recognition Time or the Activity Time or both. As the Recognition Time contributes about 56\% of the RT most can be gained by reducing this component of the RT. However, given the state-of-theart nature of the alarm system (performance stopped, house lights raised, alarm tone followed by short informative message) it is difficult to suggest how the Notification Time component of the Recognition Time for the theatre could be improved. The long Recognition Time is partly due to the high number of Information Tasks (not measured) that occur during the Response Phase. This may be due to the population needing to collect additional information to verify that they do indeed need to evacuate. Perhaps this component of the Recognition Time could be reduced if a shorter more precise alarm message was used (alarm message requires about $15 \mathrm{~s}$ to complete one cycle). In addition, the theatre staff could take a more assertive role, not only indicating which exits to use but also assertively encouraging the population to start to evacuate.

The other way of reducing the overall RT is to reduce the time expended in the Activity Stage. Ideally, occupants would not need to perform any Action and Information Tasks or at the very least no Action Tasks during the Activity Stage. Clearly, if the occupants did not have the need to perform any tasks during the Activity Stage, the average RT could be reduced by 24.8 s on average (see Table 2). A significant proportion of this time saving could be achieved by encouraging the population not to bring so many personal items into the auditorium that require immediate collection prior to evacuation thus removing the need to perform Action Tasks. It is accepted that this approach to reducing the RT may be more difficult to achieve than addressing the Recognition Time. However, it is also suggested that the RT may be expected to be longer in colder climates then the one in which the trial was undertaken, where a greater proportion of the population may be expected to have coats and conversely, may be expected to be shorter in warmer climates where fewer of the population will have the need to bring coats.

It is noted that the Swedish cinema evacuation trials [16] took place on different days and different months. The two alarm bell trials took place on $10^{\text {th }}$ and $11^{\text {th }}$ of September 1999 while the three voice alarm trials took place on the $5^{\text {th }}, 8^{\text {th }}$ and $9^{\text {th }}$ of October 1999. It is not known what time of day the trials took place, but the high/low temperatures on these days were reported to be $22 / 11.7 \mathrm{C}, 22.8 / 10.6 \mathrm{C}, 15.2 / 6.8 \mathrm{C}, 14.7 / 10 \mathrm{C}$ and $12.6 / 9 \mathrm{C}$ respectively [19]. While the temperatures appear consistent for the two bell trials and three voice trials, the temperatures between the two types of trial are quite different, with the voice trials occurring on much cooler days. It is possible that a higher proportion of the audience had coats for the voice alarms, requiring the audience to undertake a greater number of Action Tasks prior to evacuating thereby influencing the response times observed.

\section{Response Time Based on Seat Location}

While an earlier study into evacuation from a seated auditorium (cinema) suggested that there was no relation between relative seating location and RT [16], the RT distribution for the theatre was examined to determine whether such a relationship could be established. To determine whether there is a geometrical relationship between RT and location it is necessary to define a grid to describe the seating arrangement within the stalls region of the theatre. The grid system utilises seat row number to identify in which row a person is located and seat number to identify where on the seat row the person is located. 
The seating in the lower stalls of the theatre are arranged in a semi regular grid. Long seating rows run parallel to the stage and are identified using a seat row number. The seat row number runs from 1 , closest to the stage, to row 11, the last row in the lower stalls. The seat numbers run from seat 1 on the right (facing the stage) to a maximum seat number of 32 on the left. Note seat row 12 is the first row in the upper stalls and is not considered in this analysis.

Running parallel to and just in front of row 1 is an aisle called longitudinal aisle 1 which connects to two other aisles, called perpendicular aisle 1 (right) and perpendicular aisle 2 (left). Just behind the last row of seats (seat row 11) is another aisle, called longitudinal aisle 2. The two exits through which $84 \%$ of the stalls population entered the auditorium are located on the right side (closest to the seat number 1 in each seat row) in the vicinity where the longitudinal aisles and perpendicular aisle 1 cross - these are identified as Main Exits (see Figure 13). The two exits through which only $16 \%$ of the stalls population entered the auditorium are located on the left side (closest to the last seat (largest seat number) in each seat row) in the vicinity where the longitudinal aisles and perpendicular aisle 2 cross - these are identified as Secondary Exits (see Figure 13). The seat number indicates how far a seat is from a perpendicular aisle and hence free access to an exit point (either the Main or Secondary Exits) while the seat row number indicates how far a seat row is from an exit point.

The population RT distribution was first analysed to determine whether RT was related to the distance to a perpendicular aisle. Distance from a perpendicular aisle is measured not in metres but in number of seats. As there is a perpendicular aisle at either end of a seat row, both the first and last seat in each row is just one seat away from a perpendicular aisle, the second and second last seat are two seats away from a perpendicular aisle etc all the way to the $16^{\text {th }}$ and $17^{\text {th }}$ seats in a 32-seat seat row, which are both 16 seats away from an aisle.

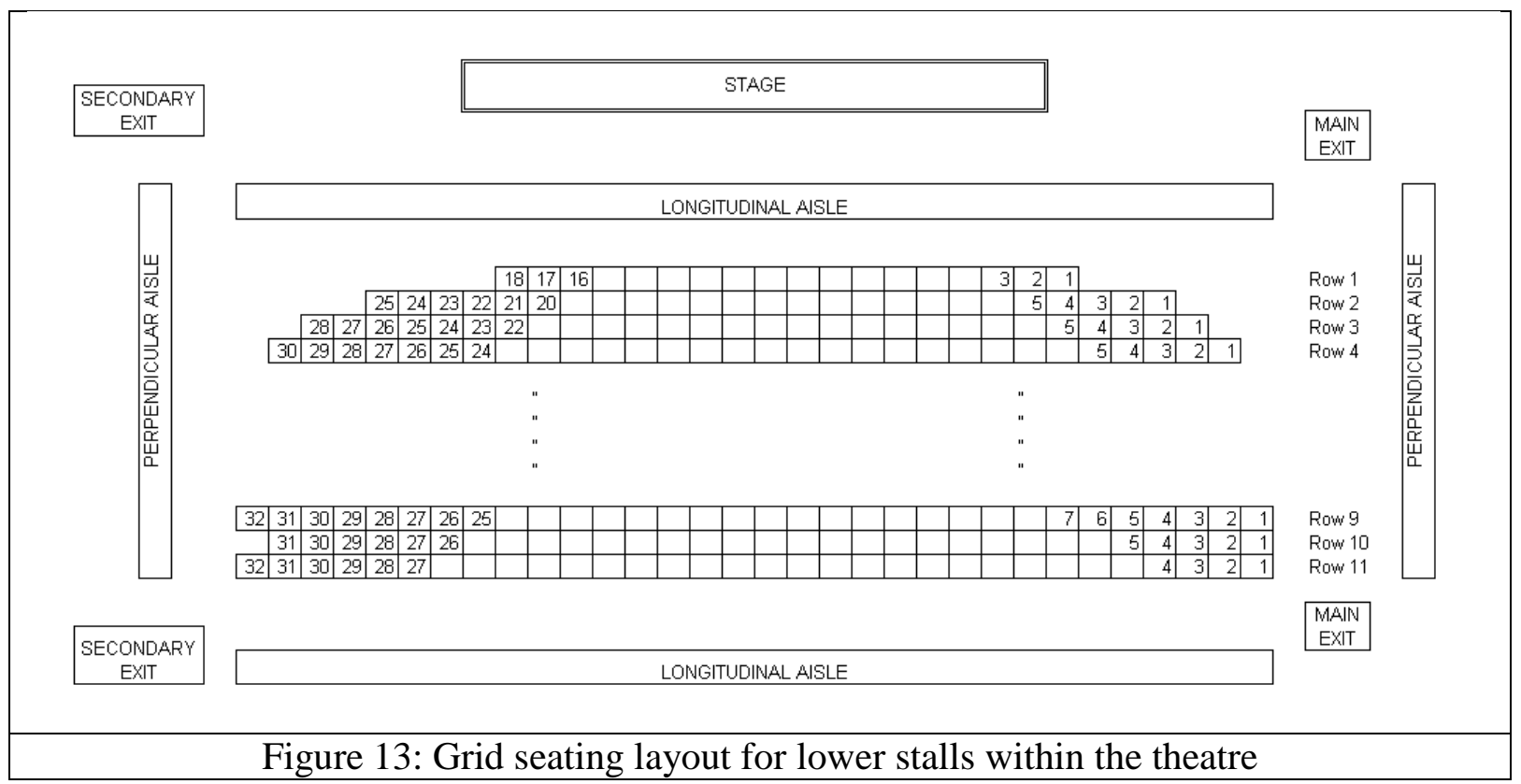

Thus seat number is an indication of relative physical distance to a perpendicular aisle. The average RT was determined for all the people located a given number of seat locations from a 
perpendicular aisle. Thus the RT of all the people who are located one seat from a perpendicular aisle - taken across all seat rows and from both the left and ride side of the seat row - are combined to determine the average RT for a person at this distance from a perpendicular aisle. Thus up to 22 individual response times contribute to average RT at each seat location. Seat 16 was excluded from this analysis due to a limited amount of data being available, there being only 10 out of a possible 22 data points available for analysis. Furthermore, the people seated in seat row 6, seats 1,2 and 3 were excluded from the analysis as they were deemed to begin their Response Phase just prior to the sounding of the alarm.

Presented in Figure 14 is the distribution of RT as a function of seat location, where the seat location is a measure of the distance to the nearest perpendicular aisle leading directly to an exit. It is clear that the average RT follows an increasing linear relationship (regression coefficient of 0.91) based on seat number, where the larger the seat number (i.e. the further away from an exit aisle), the larger the RT (see Figure 14a). The distance to the perpendicular aisle can also be separated into distance to the left or right perpendicular aisle. When this is done it is found that both the left and right follow a similar linear relationship (see Figure 14b). Thus the RT appears to generally increase with increasing distance from the perpendicular exit aisle, reaching a maximum when located towards the centre of the seat row.

Thus those with easy access to the perpendicular exit aisle react quickest, and those who are furthest away from clear access to the perpendicular exit take longest to react. This may be due to the expectation that those located towards the middle of the row will be unable to move before those closer to the perpendicular exit aisle have moved.

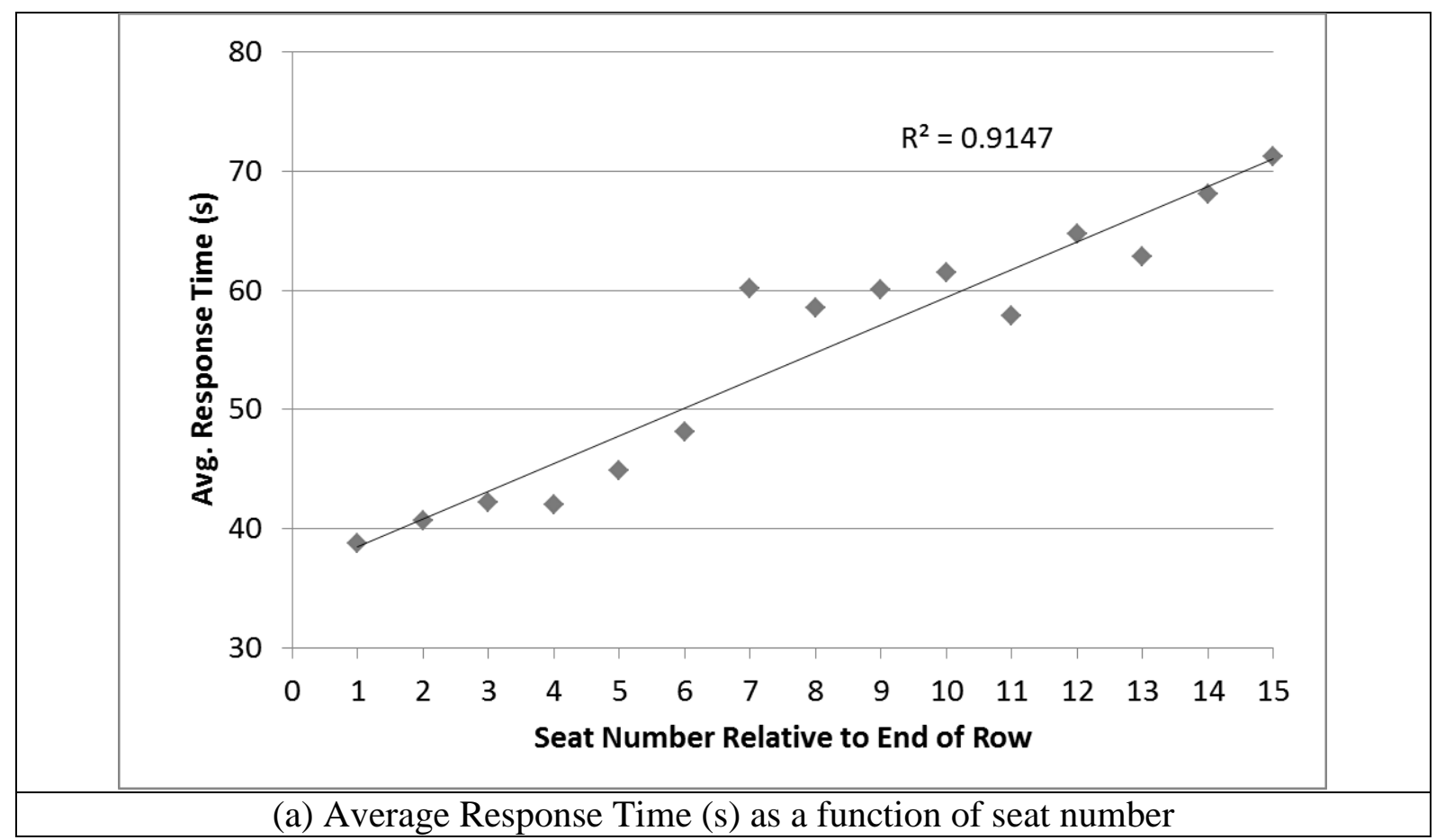




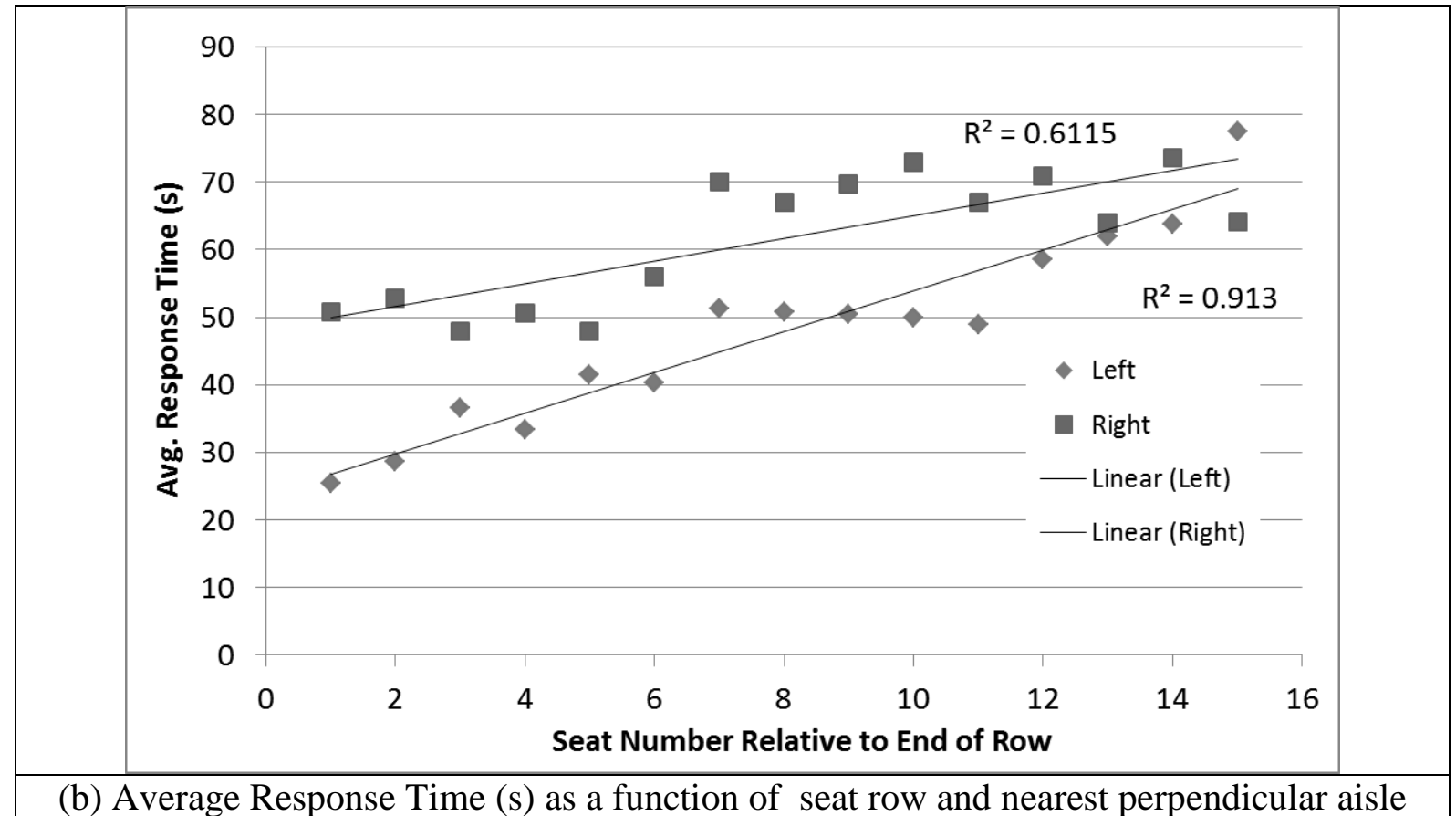

Figure 14: Average response time based on seat location

However, seats located on the right of the theatre have lower RT compared to equivalent seat locations on the left and the rate of increase in RT with seat location is slightly greater for seats located on the right. Indeed, the average RT for seats located on the right of the theatre is $48.7 \mathrm{~s}$ while the average for those on the left is $61.2 \mathrm{~s}$ a difference of $26 \%$. This difference is statistically significantly different (Mann-Whitney $\mathrm{U}=17911.5, \mathrm{n} 1=166, \mathrm{n} 2=161, \mathrm{P}<0.001$, two tailed). The reason for the difference in RT for the left and right part of the theatre is not clear but may be due to the location of the main entrances to the theatre complex and the auditorium being located on the right side. While there are exits also located on the left side (with easy access from the left perpendicular exit aisle), it was noted that $84 \%$ of the population entered the auditorium using the right exits and so the population is most familiar with the exits on the right. Thus, most people will have the expectation (at least initially) of exiting the auditorium and theatre complex from the right hand side.

Those initially located on the left are thus far removed from what is perceived (at least initially) to be the main entrance and so anticipate that there will be a lengthy queue at the exits formed by those who are more closely situated to the exits. They are thus likely to be less inclined to rush their response, resulting in the longer average response times for those situated on the left. Those located on the right are closest to what are perceived to be the main exits and so realise that if they do not delay their response, they may be able to quickly exit the auditorium avoiding the eventual lengthy queues formed by those that that located further away. Thus the people located on the right (near the perceived main exits) are more likely to hasten their response compared to those that are located further away.

This conjecture is supported by the observation that those with the shortest RT i.e. those that are adjacent to the perpendicular exit aisle display the greatest difference in RT for the left and right locations. Those who located nearest to the end of the row (closet to the right perpendicular exit aisle) have the most to gain by reacting quickly and so produce the shortest RTs. 
The population RT was also analysed based on seat row number. In this case, all the RT for each seat location within a row was combined and an average RT was produced for the seat row. Seat rows 1 and 2 were omitted from this analysis for two reasons, first they had the smallest number of occupied seats compared to the other rows - all the other rows had between 28 and 32 occupied seats, and secondly, these seat rows were configured differently to all the others, providing greater easy access to the longitudinal aisle at the front of the theatre than all the other seat rows. Thus seat rows 3 to 11 provided a selection of seat rows with uniform seating conditions with almost identical occupancy.

The seat row average RT data is presented in Figure 15. As can be seen in Figure 15, with the exception of seat row 4, there is a clear pattern in RT behaviour, with rows closer to the front and rear longitudinal exit aisle, having the shorter average RT, with the average RT increasing the further away the seat row is located from a longitudinal exit aisle and peaking at seat row 7. The reason that seat row 4 has an unusually long RT is believed to be related to the behaviour of four elderly people who appear to be part of a social group located in the central four seats on the left. They take some time in apparent discussion deciding what to do, one of the group does not get up from his seat for some time, and then begins to search under and around his seat for something. The members of the group then assist each other putting on their coats before finally starting to move.

The reason for the observed trend in seat row average RT is thought to be similar to that for the seat number RT trend. As the exit points in the auditorium are located near the first and last seat rows, those located closest to the exit point (low and high seat row numbers) will react quickest as they are less likely to have many people ahead of them compared to those located in seat rows further away, and so they will be able to exit in the shortest possible time. Conversely, those located furthest away (middle seat row numbers) will react the slowest as they realise that many other people are likely to be ahead of them irrespective of how fast they react.

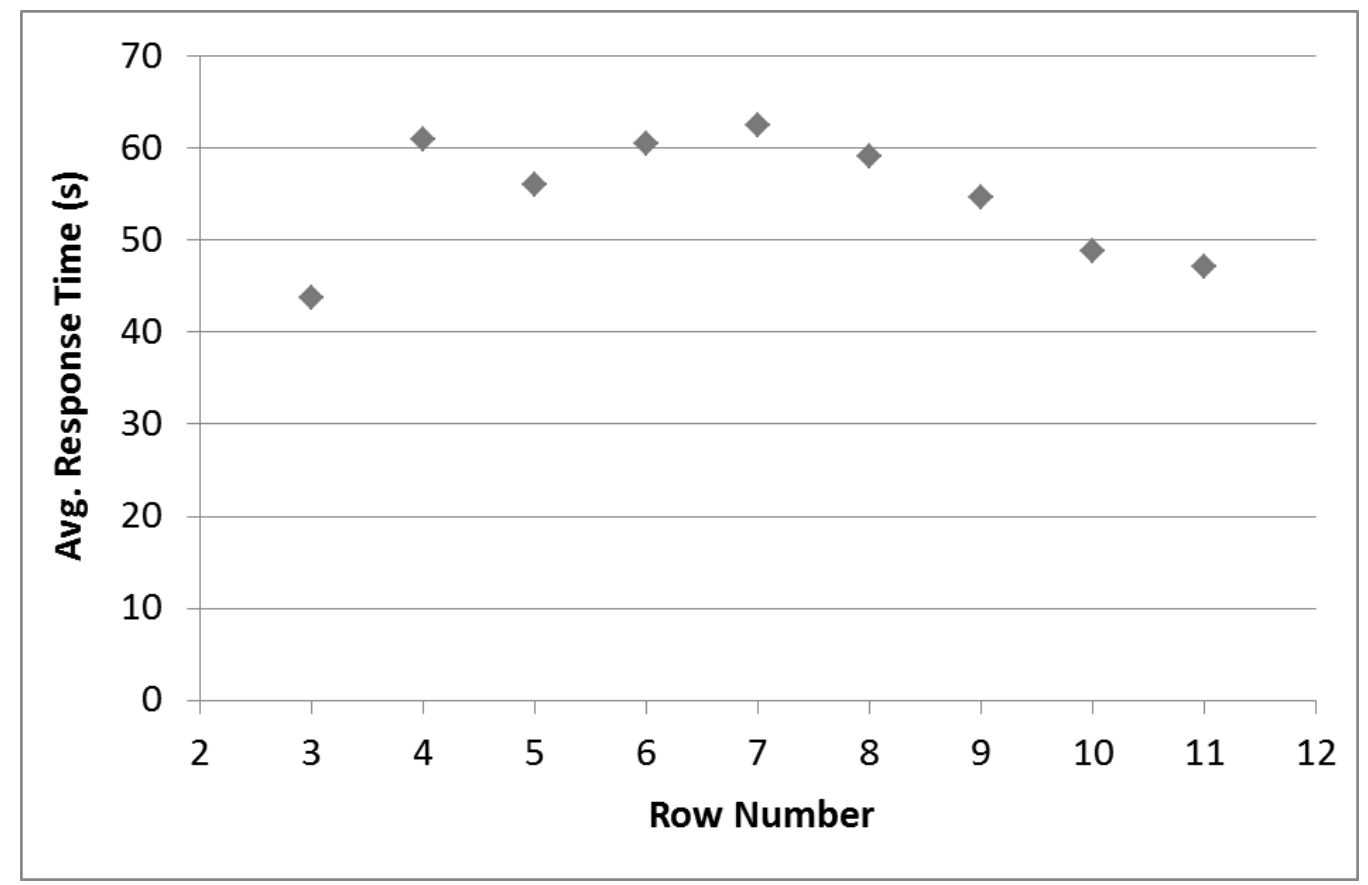

Figure 15. Average Response Time Based on Seat Row Number 
This analysis has shown that there is a clear structure to the RT distribution within the theatre, with RT generally increasing linearly the further a seat within a seat row is removed from an exit aisle and the further the seat row is removed from an exit aisle. Thus the seat location relative to exit aisles appears to be a good predictor of RT. This is a significantly different behaviour to that observed in the earlier work [16] which did not observe a strong relationship between seat location and RT. The differences in the results may be due to a number of factors such as; the small size of the sample population observed in the Swedish experiments (which was $40 \%$ of the size of the current sample), the small physical size of the cinema in the Swedish trials, the layout of the Swedish cinema (single main exit located at rear) or all of the above.

\section{Redistribution Model for Response Times}

From the above analysis it is clear that the RT distribution within the theatre is strongly influenced by occupant seating location. Thus if the log-normal distribution given by equation 1 was to be used to generate RTs for the theatre population and they were randomly distributed throughout the theatre, as is typically undertaken in evacuation simulation using software such the buildingEXODUS [3], then the structure in the RT distribution would be lost. Presented in Figure 16 is the 'experimental' and 'model' RT as a function of seat number (see Figure 16a) and seat row (see Figure 16b). The 'experimental' curve is determined using the actual RTs measured during the trial and placed in the seat location in which they occurred. In contrast, the 'model' curve is determined using the actual RTs measured during the trial but randomly allocated to seat locations. As can be seen, the randomly allocated predicted RTs do not generate the same trends of RT with seat number and seat row as observed in the actual data. As a result, unrealistic results are likely to be produced by the simulation software, with predicted evacuation times likely to be too long or too short and as a result issues relating to the formation of critical congestion may not necessarily be observed.

When allocating RTs to seat locations it is thus necessary to allocate the RTs in a manner that preserves the observed structure of the RT distribution. To achieve this, the general pattern in RT distribution is followed assuming that the RT increases from the outer seat locations inwards and from the outer seat rows inwards. Thus an allocation model as depicted in Figure 17 is suggested. The allocation model is here demonstrated for an auditorium with 6 seats per row and 5 seat rows. To achieve this, the RTs ordered from the lowest to the largest and distributed according to the model presented in Figure 17.

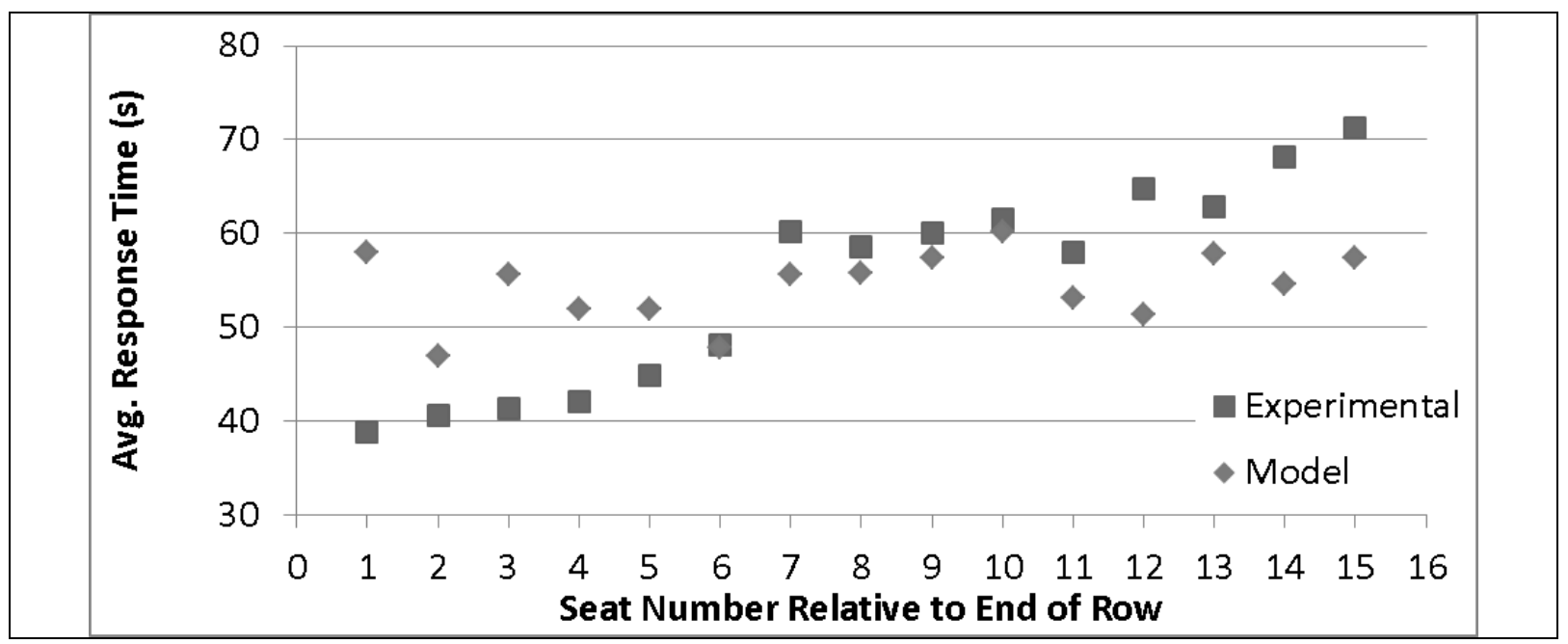




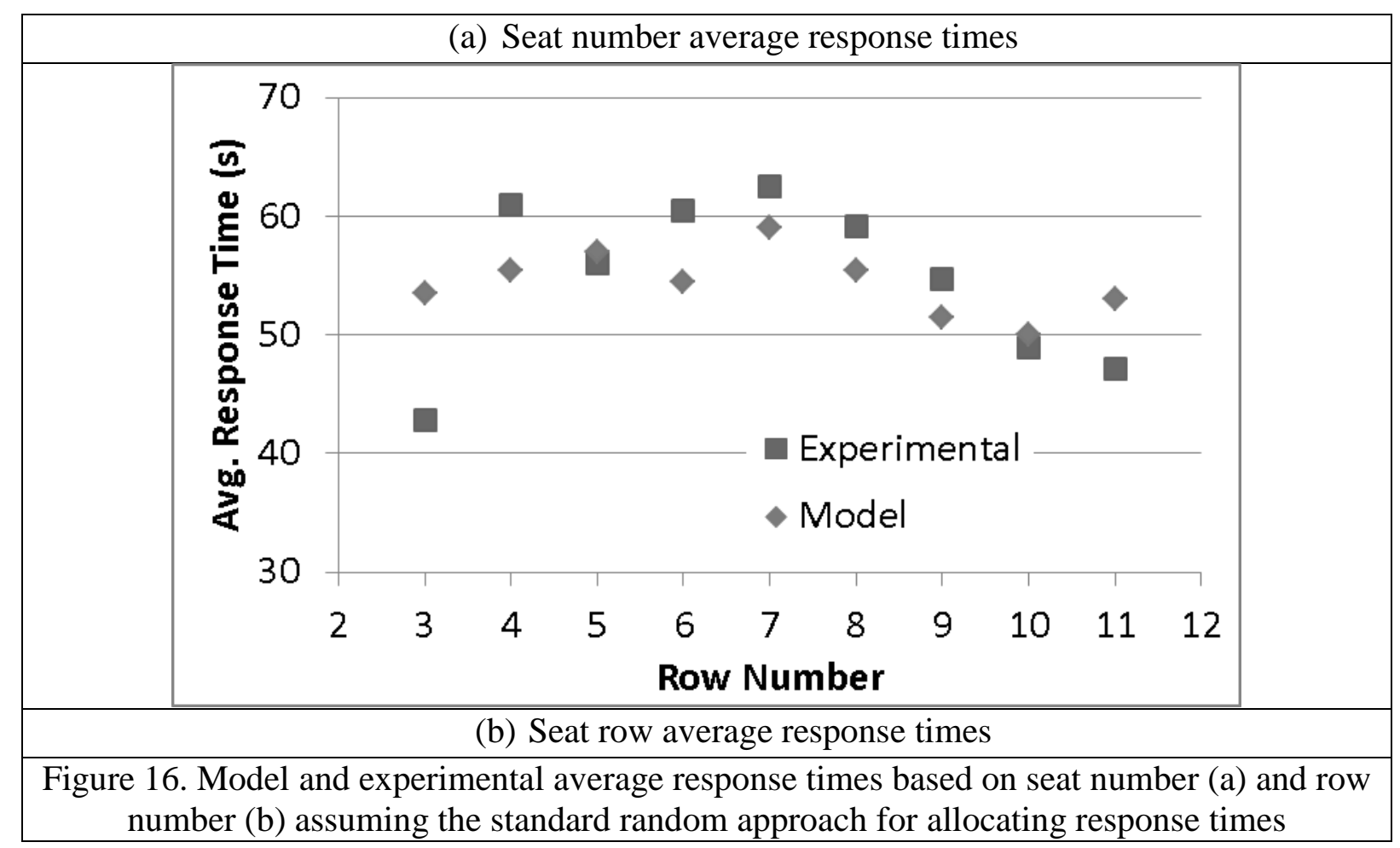

The allocation model presented in Figure 17 assumes that the RTs exactly follow the pattern described. However, it is clear from the observations that while the observed trends are generally followed they are not rigidly followed (see for example Figure 14 and Figure 15). In an attempt to introduce some of the violations to the observed general trends, a certain amount of randomisation can be introduced into the distributed RTs. So for example, once the RTs are distributed according to Figure 17, a certain percentage of the RTs can be randomly redistributed. Here we explore the impact of randomly distributing 10\%, $20 \%$ and $30 \%$ of the RTs (see Figure 18 and Figure 19).

\begin{tabular}{|l|l|r|r|r|l|l|}
\hline Row 5 & 3 & 13 & 23 & 24 & 14 & 4 \\
\hline Row 4 & 7 & 17 & 27 & 28 & 18 & 8 \\
\hline Row 3 & 9 & 19 & 29 & 30 & 20 & 10 \\
\hline Row 2 & 5 & 15 & 25 & 26 & 16 & 6 \\
\hline Row 1 & 1 & 11 & 21 & 22 & 12 & 2 \\
\hline SEAT & $\mathbf{1}$ & $\mathbf{2}$ & $\mathbf{3}$ & $\mathbf{4}$ & $\mathbf{5}$ & $\mathbf{6}$ \\
\hline
\end{tabular}

Figure 17. Response time allocation model demonstrated for an auditorium with 6 seats per row and 5 seat rows 


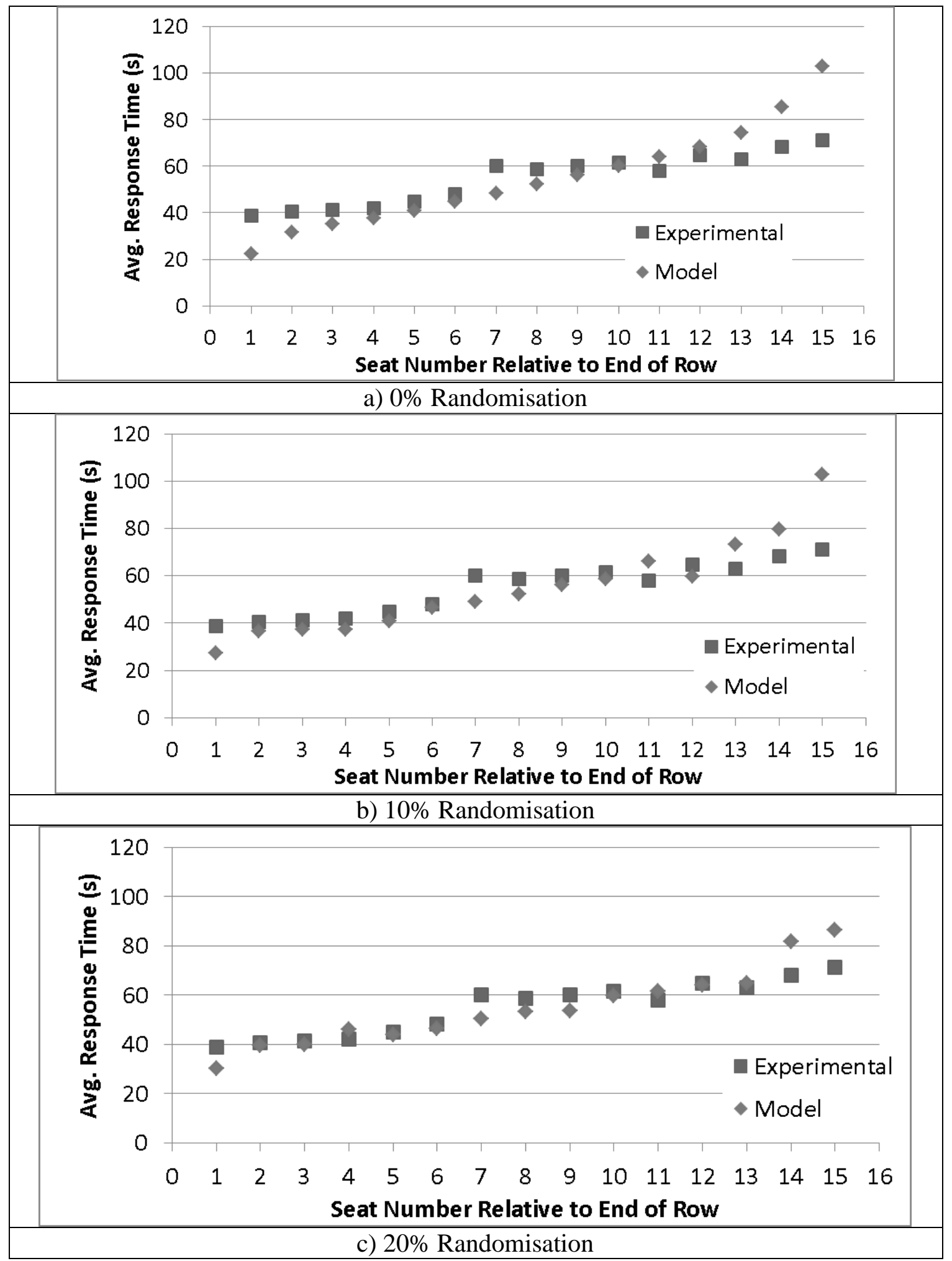




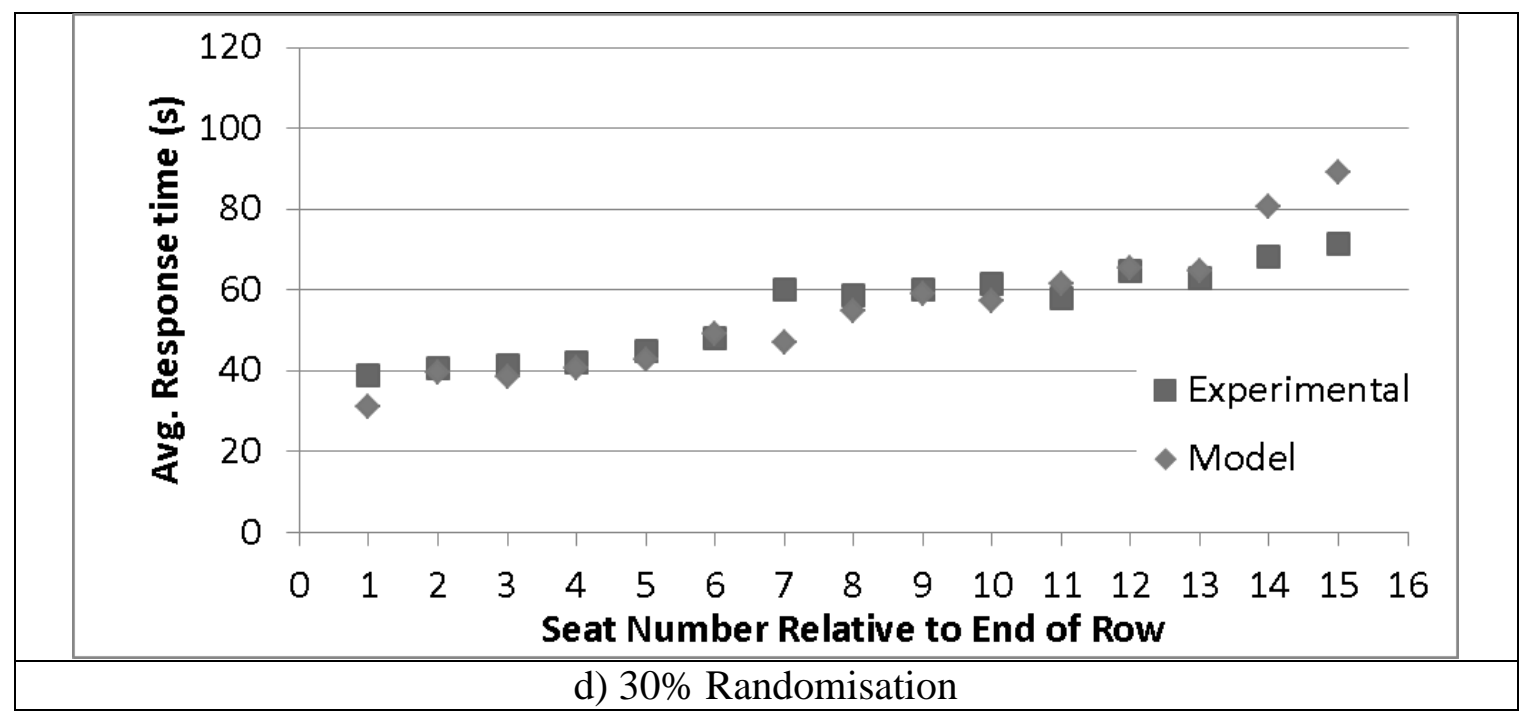

Figure 18. Average response time as a function of seat number (experimental and model data)

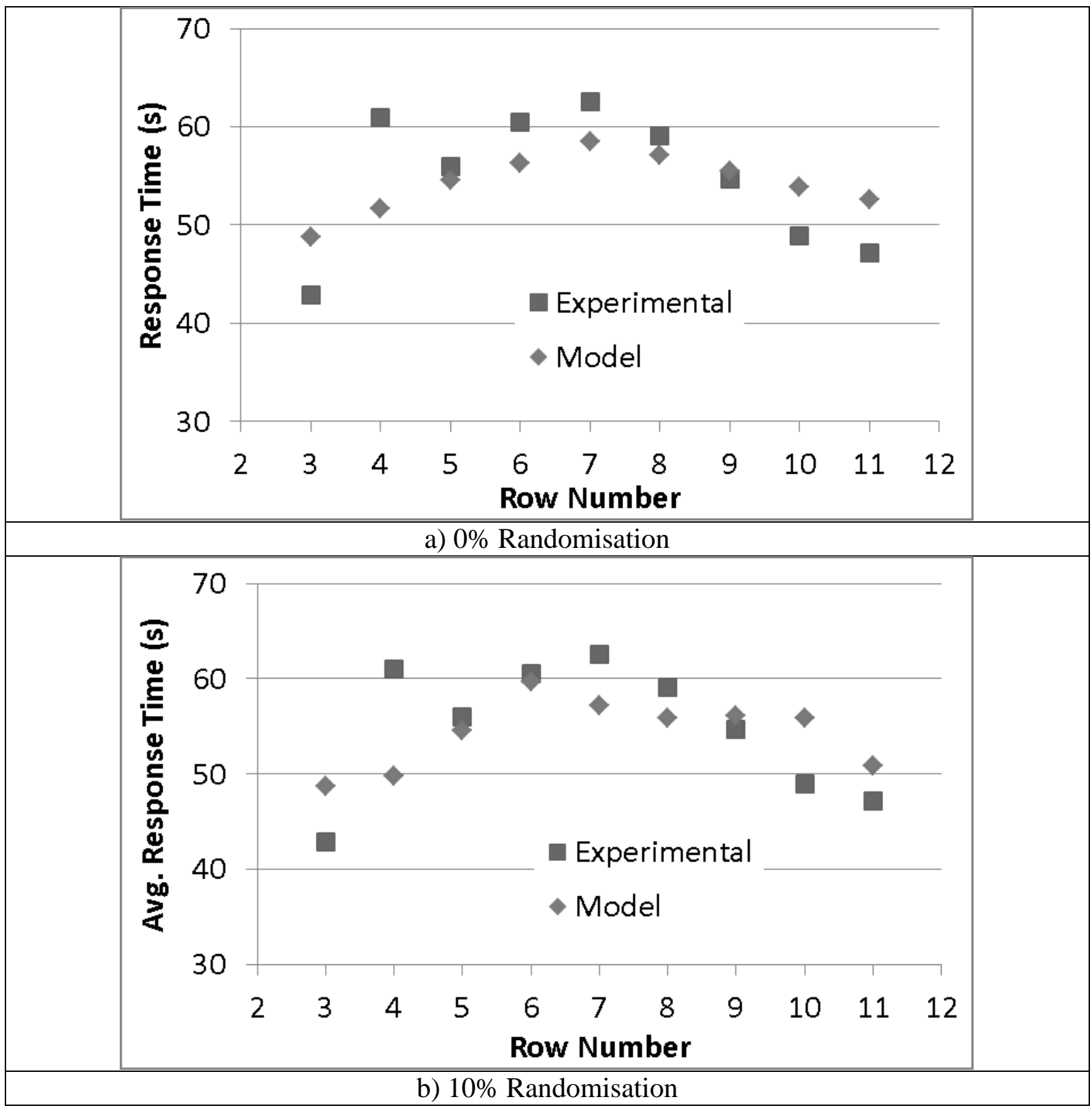




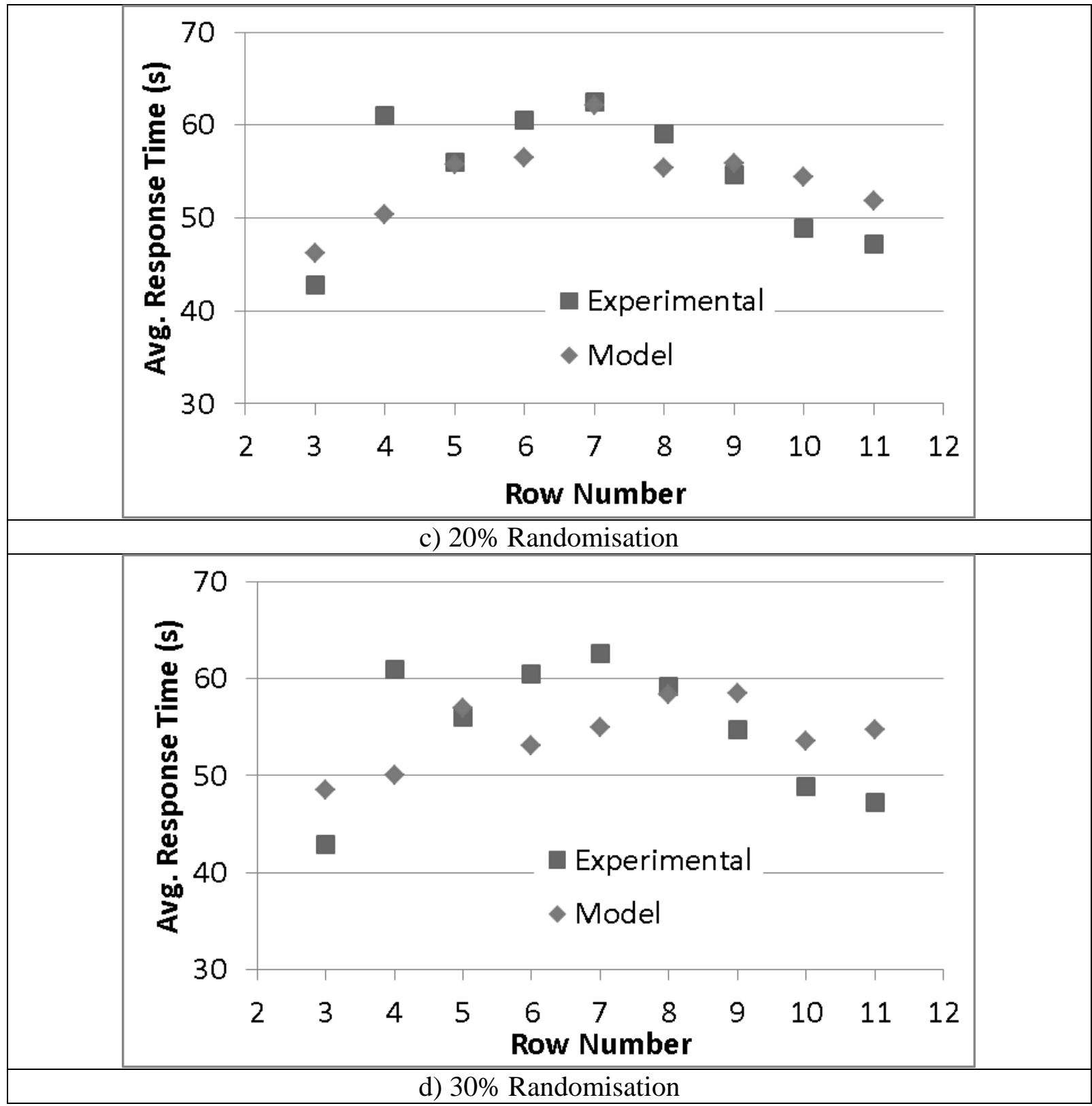

Figure 19. Average response time as a function of seat row number (experimental and model data)

As can be seen from Figure 18a and Figure 19a, without randomised redistribution, the allocation model defined by Figure 17 works very well and maintains the general trends observed in the measured data regarding seat number (see Figure 18a) and seat row (see Figure 19a). This is clearly an improved representation than that generated by the purely random allocation of RT as depicted in Figure 16. The RT allocation according to the distribution model with a $10 \%, 20 \%$ and $30 \%$ randomisation is presented in Figure $18 \mathrm{~b}$ and Figure 19b; Figure 18c and Figure 19c; and Figure 18d and Figure 19d respectively. Arguably, from a visual inspection of the various curves, the $20 \%$ randomisation produces the best overall agreement.

However, to determine which of the approaches fits the experimental data best a measure of the goodness of fit between the model and experimental data is required. Here we make use of the Euclidean Relative Difference (ERD) to measure the goodness of fit as presented in 
equation 2 and the Secant Cosine (SC) as presented in equation 3 [20]. The ERD is used to assess the average difference between the RT distribution model $\left(\mathrm{m}_{\mathrm{i}}\right)$ and the observed data $\left(\mathrm{E}_{\mathrm{i}}\right)$, with the smaller the ERD the better the fit.

$$
\begin{gathered}
\frac{\|E-m\|}{\|E\|}=\frac{\sqrt{\sum_{i=1}^{n}\left(E_{i}-m_{i}\right)^{2}}}{\sqrt{\sum_{i=1}^{n} E_{i}^{2}}} \\
\frac{\langle E, m\rangle}{\|E\| \mid m \|}=\frac{\sum_{i=s+1}^{n} \frac{\left(E_{i}-E_{i-s}\right)\left(m_{i}-m_{i-s}\right)}{s^{2}\left(t_{i}-t_{i-1}\right)}}{\sqrt{\sum_{i=s+1}^{n} \frac{\left(E_{i}-E_{i-s}\right)^{2}}{s^{2}\left(t_{i}-t_{i-1}\right)} \sum_{i=s+1}^{n} \frac{\left(m_{i}-m_{i-s}\right)^{2}\left(t_{i}-t_{i-1}\right)}{2}}}
\end{gathered}
$$

Unlike the ERD, the SC provides a measure of how well the shape of the model data curve matches that of the experimental data curve. It makes use of the first derivative of both curves. The SC measure includes a 'smoothing' term, s, which attempts to remove noise in both the experimental data and the model prediction. Selecting an appropriate value of $\mathrm{s}$ is dependent on the number of data points in the data-set, given by n. It is desirable to keep the ratio $\mathrm{s} / \mathrm{n}$ as low as possible. Typically the value of $\mathrm{S} / \mathrm{n}$ should fall in the range 0.01 to 0.1 with steps of 0.01 . An SC of 1.0 suggests that the shape of the model $\left(\mathrm{M}_{\mathrm{i}}\right)$ curve is identical to that of the experimental $\left(\mathrm{E}_{\mathrm{i}}\right)$ curve. In this analysis the value of $\mathrm{S} / \mathrm{n}$ is 0.06 .

Presented in Table 3 are the ERD and SC values for the various distribution models. ERD and SC values are determined for both the row RT distribution curve (see Figure 18) and the seat RT distribution curve (see Figure 19). Cleary the ERD and SC values will be different for each assessment and a given level of randomisation will not necessarily produce similar goodness of fit for each of the two assessments. This is because the observed trends that we are attempting to emulate are not as strong in both cases, with the observed trend in seat row not being as strong as the observed trend in seat number.

Based on seat number, the best ERD is achieved for the $20 \%$ randomisation model with the worst ERD being the $0 \%$ randomisation model. Based on the seat row number the $20 \%$ randomisation model again produces the best ERD with the $30 \%$ producing the worst ERD. To determine the best overall ERD the values for both curves are simply added, with the smallest overall value deemed to provide the best overall fit (see Total ERD row in Table 3). As can be seen from Table 3, the 20\% randomisation model produces the best overall ERD while also producing the best ERD for each of the two curves. This suggests that the 20\% randomisation model produces the smallest difference in absolute terms from the experimental values. It is also worth noting that the $0 \%$ randomisation case produces the worst ERD suggesting that using the theoretical distribution without introducing any randomisation produces the largest overall difference between the model and experimental values. 
While the ERD measures the distance between the experimental and model curves, the SC measures how well the shape of the two curves agree. This is also important as the shape of the curve provides an indication of the relative trends in the data. Based on seat number, the best SC is achieved for the $20 \%$ randomisation model with the worst SC being the $10 \%$ randomisation model. Based on the seat row number the $0 \%$ randomisation model produces the best SC with the $30 \%$ producing the worst SC. As with the ERD, the SC for the two curves is combined to determine the best overall $\mathrm{SC}$, with the largest overall value deemed to provide the best overall fit (see Total SC row in Table 3). As can be seen from Table 3, the $0 \%$ randomisation model produces the best overall SC with the $20 \%$ randomisation producing the second best SC. Unlike in the case for the ERD, one randomisation model does not produce the best $\mathrm{SC}$ for both curves. It is also noted that while the $0 \%$ randomisation model produces the best overall SC, it also produced the worst ERD. Overall, the 20\% randomisation model is considered to produce the best fit with the experimental data, being best in three of the four categories, producing the best overall ERD and the second best SC. This also supports the conclusion made simply using a visual inspection of the various curves. Thus it is suggested that the $20 \%$ randomisation model should be used when distributing RTs in theatre models.

\section{CONCLUSIONS}

The results presented in this paper are based on an unannounced theatre evacuation involving some 1200 people in which a voice alarm system was used, in conjunction with several other cues including, house lights coming on, performance stopping and stage fire curtain descending. The Response Phase behaviours of 338 people seating in the stalls of the auditorium were collected and analysed. It must be emphasised that in this work the response time is not the time between the sounding of the alarm and when people begin purposeful movement towards an exit. This is because due to the nature of the geometry, while people may be ready to move towards an exit they may be prevented from doing so due to congestion within the seat rows.

The response times for the population were found to follow the typical log-normal distribution found for other building types, with an average response time of $55.6 \mathrm{~s}$. Thus on average $1 \mathrm{~min}$ was required to prepare the population to commence their physical evacuation. However, an important observation, not noted in other evacuation experiments was that response time was related to a person's seat position, where seat position is considered to be a function of two variables, distance (measured in seats) along the seat row from an aisle and distance (measured in seat rows) of the seat row from an exit. Thus seat location relative to an access aisle and exit point was a good predictor of response time.

These trends in response time distribution may have a profound impact on analysis of evacuation times and congestion levels determined by agent based evacuation models and so should be represented within these models. Clearly, the fully random approach used by evacuation models is not appropriate for theatre applications. A methodology to distribute response time within the theatre was suggested which included an up to $20 \%$ randomisation to reflect the observation that the observed trends were not strictly adhered to in the experimental observations. However, it is not clear if the proposed theatre response time distribution model can be generalised to other theatres and if so under what conditions. Further experimental analysis is required to determine whether these observations can be generalised, but if so, it would be a powerful approach with possible application to other seated venues such as cinemas, music venues and sports arenas. 
The Response Phase behaviours were analysed using a previously proposed behavioural framework. The framework is useful as it provides a systematic way to analyse Response Phase behaviours thereby explaining response times and hence identifying possible means of improving Response Phase behaviour and response times. Using the terminology of the framework it was determined for this particular evacuation, $56 \%$ of the response time was due to the Recognition Time while $44 \%$ was due to the Activity Time.

During the Recognition Time, participants disengage from their pre-alarm activity (Notification Stage) and assess the behaviour of others and the state of the environment (performing Information Tasks) and formulate a course of action. In this particular evacuation it was suggested that it may be possible to reduce the response time by having staff not only point out the available exits but assertively encourage people to start the evacuation process, reducing the need to perform as many Information Tasks and thereby reducing the Recognition Time.

During the Response Phase, people undertook on average 0.62 Action Tasks, which included activities such as putting on coats, collecting bags etc. However, over 55\% of the population did not undertake a single Action Task and simply stood up, after a Recognition Delay, performing an unmeasured number of Information Tasks prior to being ready to commence purposeful movement to an exit. While males undertook fewer Action Tasks than females, they took longer to perform those tasks and required longer to disengage from the preevacuation task and engage in the evacuation and as a result, the average response time for males was $57 \mathrm{~s}$ and for females $55 \mathrm{~s}$. The difference between the male and female response times was not found to be statistically significantly different.

During the Activity Stage the most frequently observed Action Task was associated with collecting and putting on coats, accounting for $64 \%$ of all Action Tasks and being performed by $39 \%$ of the population. As a result, it was suggested that the response time may be expected to be longer in colder climates then the one in which the trial was undertaken, where a greater proportion of the population may be expected to have coats and may be expected to be shorter in warmer climates where fewer of the population will have the need to bring coats.

\section{ACKNOWLEDGEMENTS}

The authors are indebted to Kent Fire and Rescue Service, in particular Paul Grimwood, Principal Fire Engineer and the Management and staff of the Marlowe theatre, and General Manager Paula Gillespie, for allowing FSEG to participate in the evacuation exercise. The authors are also indebted to the audience of the Marlowe Theatre for their patience, tolerance and good nature.

\section{REFERENCES}

1. Galea, E.R., "Evacuation Response Phase Behaviour," Paper No. 09/IM/147, October 2009. University of Greenwich. London: CMS Press. ISBN No: 978-1-904521-62-4

2. Galea, E.R., Filippidis, L., Deere, S.J., and Sharp, G., "Behaviour - Security Culture. Human behaviour in emergencies and disasters: A cross-cultural Investigation.”, Silke Schmidt and Ed Galea (Eds), pp 131-215, 2013, Pabst Science Publishers. ISBN: 978-3-89967-867-3. 
3. Galea, E.R., Sauter, M., Deere, S.J., Filippidis, L., Investigating the Impact of Culture on Evacuation Behaviour - A Turkish Data-Set". Proceedings of the Tenth International Symposium on Fire Safety Science, University of Maryland, 19-24 June 2011, pp. 709-722. ISSN 1817-4299. DOI: 10.3801/IAFFS.FSS.10-709.

4. British Standards Institute, DD240: part 1: 1997.

5. ISO Technical Report, Fire Safety Engineering - Part 8, Life Safety - Occupant behaviour, location and condition, ISO/TR 13387-8:1999.

6. Proulx, G., "Movement of People: The Evacuation Timing", SFPE Handbook of Fire Protection Engineering, $3^{\text {rd }}$ ed, National Fire Protection Association: Quincy, 2002, pp 3-342 to pages 3-366.

7. British Standards Institution. The application of fire safety engineering principles to fire safety design of buildings, PD7974-6: Human Factors: Life safety strategies occupant evacuation, behaviour and condition, 2004.

8. Brown, R., Galea, E.R., Deere, S.J., Filippidis, L., Passenger Response Time Datasets for Large Passenger Ferries and Cruise Ships Derived from Sea Trials, Transactions of the Royal Institution of Naval Architects, International Journal of Maritime Engineering, Vol 155, Part A1, pp 33-48, 2013.

9. Kuligowski, E.D., and Mileti, D.S., Modeling pre- evacuation delay by occupants in World Trade Center Towers 1 and 2 on September 11, 2001, Fire Safety Journal 44 (2009) 487-496 doi:10.1016/j.firesaf.2008.10.001.

10. Gwynne, S.M.V., Notification Effectiveness for Large Groups, Report for The Fire Protection Research Foundation, Grant No. EMW-2005-FP-O1258, June 8, 2007

11. Proulx G., Evacuation Time, SFPE Handbook of Fire Protection Engineering, $4^{\text {th }}$ Edition, Editors: Philip J DiNenno, et al, Library of Congress: 2007940503, 2008, pp 3-355 - 372.

12. Frantzich, H Occupant behaviour and response time results from evacuation experiments, Proceedings of the $2^{\text {nd }}$ International Symposium on Human Behaviour in Fire, Massachusetts, 2001, pp159-165.

13. Shields T., J., Boyce K., E, A study of evacuation from large retail stores. Fire Safety Journal, Vol 35, N1, 2000, pp 25-49.

14. Boyce, K., McConnell, N., Shields, J., A study of human behaviour during evacuation of licensed premises, Proceedings of the $6^{\text {th }}$ International Symposium on Human Behaviour in Fire, Cambridge, 2015, pp373-165.

15. Bayer, K., Rejno, T., Evacuation alarm optimizing through full-scale experiments, Report 5053, The Department of Fire Safety Engineering, Lund University, Lund, 1999 (in Swedish).

16. Nilsson, D., Johansson, A., Social influence during the initial phase of a fire evacuation-analysis of evacuation experiments in a cinema theatre, Fire Safety Journal, Vol 44, issue 1 (2009), pp. 71-79, doi:10.1016/j.firesaf.2008.03.008

17. Kennedy, M (2011). Marlowe theatre: curtain rises on Canterbury’s $£ 25.6 \mathrm{~m}$ revamp. [online] The Guardian. Available at: http://www.theguardian.com/stage/2011/sep/28/new-marlowe-theatre-canterbury [Accessed 24 Sep. 2014]. 
18. Canterbury City Council, the Marlowe Theatre (2011), "Download our seating plan". [Online]. Available at: http://www.marlowetheatre.com/page/3182/Download-ourseating-plan [Accessed 18 March 2014].

19. Global Daily Weather-Climate Data Statistics [Online]. Available at: http://www.geodata.us/weather/show_full.php?usaf=026350\&uban=99999\&m=10\&c $=$ Sweden \&y=1999\#what

20. Galea, E.R., Deere, S., Brown, R., Filippidis, L., Two Evacuation Model Validation Data-sets for Large Passenger Ships, SNAME (The Society of Naval Architects and Marine Engineers) Journal of Ship Research, Vol 57, number 3, pp155-170, Sept 2013, http://dx.doi.org/10.5957/JOSR.57.3.120037 
Table 1: Approximate Average Activity Time (s) as a Function of the Number of Action Tasks

\begin{tabular}{|c||c|c|c|c|c|c|c|c||}
\hline \multirow{2}{*}{$\begin{array}{c}\text { no. of Action } \\
\text { tasks }\end{array}$} & \multicolumn{2}{|c|}{ Population } & \multicolumn{2}{c|}{ Male } & \multicolumn{2}{c|}{ Female } & \multicolumn{2}{c|}{ Unknown } \\
\cline { 2 - 11 } & Time (s) & $\#$ & Time (s) & $\#$ & Time (s) & $\#$ & $\begin{array}{c}\text { Time } \\
(\mathrm{s})\end{array}$ & $\#$ \\
\hline 0 & - & 154 & - & 57 & - & 93 & - & 4 \\
\hline 1 & 28 & 108 & 27 & 37 & 28 & 66 & 36 & 5 \\
\hline 2 & 30 & 29 & 41 & 6 & 27 & 23 & - & - \\
\hline 3 & 42 & 7 & - & - & 42 & 7 & - & - \\
\hline
\end{tabular}

Table 2: Overall Response Phase Parameters for the Theatre Evacuation

\begin{tabular}{|l|c|c|c|c|}
\hline \multicolumn{1}{|c|}{ Average } & $\begin{array}{c}\text { Overall } \\
\text { Population }\end{array}$ & Males & Females & $\begin{array}{c}\text { \% difference } \\
\text { (Males - Females)/Males }\end{array}$ \\
\hline Response Time (s) & 55.6 & 57.2 & 54.9 & 4 \\
\hline Recognition Stage (s) & 31.2 & 33.9 & 29.6 & 13 \\
\hline Activity Stage (s) & 24.8 & 23.3 & 25.2 & -8 \\
\hline $\begin{array}{l}\text { Number of Action Tasks } \\
\text { per person }\end{array}$ & 0.62 & 0.47 & 0.70 & -49 \\
\hline Action Task Duration (s) & 25 & 26 & 23 & 11 \\
\hline \hline
\end{tabular}

Table 3. ERD and SC values for various randomisation models for the row and seat distributions

\begin{tabular}{|l||c|c|c|c|c||}
\hline & $100 \%$ & $0 \%$ & $10 \%$ & $20 \%$ & $30 \%$ \\
\hline \hline Seat number ERD & 0.173 & 0.213 & 0.193 & $\mathbf{0 . 1 2 3}$ & 0.129 \\
\hline Row number ERD & 0.097 & 0.089 & 0.098 & $\mathbf{0 . 0 8 7}$ & 0.115 \\
\hline Seat number SC & 0.19 & 0.46 & 0.16 & $\mathbf{0 . 5 1}$ & 0.34 \\
\hline Row number SC & 0.32 & $\mathbf{0 . 6 0}$ & 0.14 & 0.41 & -0.03 \\
\hline Total ERD & 0.270 & 0.302 & 0.291 & $\mathbf{0 . 2 1 0}$ & 0.244 \\
\hline Total SC & 0.51 & $\mathbf{1 . 0 6}$ & 0.30 & 0.92 & 0.31 \\
\hline
\end{tabular}

Bold: best value, Italics: worst value 